\title{
Cross-species epigenetic regulation of nucleus accumbens KCNN3 transcript variants by excessive ethanol drinking and dependence
}

Rita Cervera-Juanes ${ }^{1}$; Audrey E. Padula²; Larry J. Wilhem; Byung Park ${ }^{3}$; Kathleen A. Grant ${ }^{1}$; Betsy Ferguson $^{1 *}$; Patrick J. Mulholland²*

${ }^{1}$ Department of Neurosciences, Oregon National Primate Research Center, Oregon Health \& Science University, Beaverton, OR 97006; '2Department of Neuroscience, Charleston Alcohol Research Center, Medical University of South Carolina, Charleston, SC, 29425; ${ }^{3}$ Department of Public Health and Preventive Medicine, Oregon Health \& Science University, Portland, OR 97239

${ }^{\star}$ Corresponding authors: Betsy Ferguson: Department of Neurosciences, Oregon National Primate Research Center, Oregon Health \& Science University, Beaverton, OR 97006. TEL: (503) 533-2403; FAX: (503) 6905384; fergusob@ohsu.edu; Patrick Mulholland: Department of Neuroscience, Charleston Alcohol Research Center, Medical University of South Carolina, Charleston, SC, 29425 TEL: (843) 792-1229; FAX: (843) 7927353; mulholl@musc.edu; 


\section{ABSTRACT}

The underlying genetic and epigenetic mechanisms driving functional adaptations in neuronal excitability and excessive alcohol intake are poorly understood. Given that small-conductance $\mathrm{Ca}^{2+}$-activated $\mathrm{K}^{+}\left(\mathrm{K}_{\mathrm{Ca}} 2\right.$ or $\left.\mathrm{SK}\right)$ channels encoded by the $K C N N$ family of genes have emerged from preclinical studies as a crucial target that contributes to heavy drinking and alcohol-induced functional neuroadaptations, we performed a cross-species analysis of KCNN3 methylation, gene expression, and polymorphisms of alcohol-drinking monkeys and alcohol dependent mice. Because of the alternative promoters in $K C N N 3$, we analyzed expression of the different transcript variants that when translated influence surface trafficking and function of $\mathrm{K}_{\mathrm{ca}} 2$ channels. In heavy drinking rhesus macaques and alcohol dependent C57BL/6J mice, bisulfite sequencing analysis of the nucleus accumbens revealed a differentially methylated region in exon $1 \mathrm{~A}$ of $K C N N 3$ that overlaps with a predicted promoter sequence. The hypermethylation of KCNN3 in monkey and mouse accumbens paralleled an increase in expression of alternative transcript variants that encode apamin-insensitive and dominant-negative $\mathrm{K}_{\mathrm{ca}} 2$ channel isoforms. A polymorphic repeat in macaque KCNN3 encoded by exon 1 did not correlate with alcohol drinking. At the protein level, $\mathrm{K}_{\mathrm{ca}} 2.3$ channel expression in the accumbens was significantly reduced in very heavy drinking monkeys. Together, our cross-species findings on epigenetic dysregulation of KCNN3 by heavy alcohol drinking and dependence represent a complex mechanism that utilizes alternative promoters to impact firing of accumbens neurons. Thus, these results provide support for hypermethylation of KCNN3 by excessive alcohol drinking as a possible key molecular mechanism underlying harmful alcohol intake and alcohol use disorder. 


\section{INTRODUCTION}

Alcohol (ethanol) use disorder (AUD) is a devastating brain disease driven by complex interactions between genetic, epigenetic, and environmental factors. Excessive ethanol drinking is a leading cause of preventable death and was estimated to cost the U.S. $\$ 249$ billion in $2010, \$ 100$ billion of which was paid for by the government $(1,2)$. There are genetic factors that increase the propensity for risky drinking $(3,4)$, and genetic background influences the efficacy of treatment options for individuals with AUD (5). In addition, prolonged excessive ethanol intake produces neuroadaptations in projection neurons and neural circuits that are proposed to sustain heavy drinking (6-8). Although there are three FDA-approved pharmacotherapies for treating AUD, only one (i.e., naltrexone) targets genetic variation in individuals with AUD and the others do not address adaptations that facilitate altered firing properties in neurons. While pharmacologically targeting known polymorphisms can reduce relapse rates in a subpopulation of individuals with AUD $(5,9)$, there have been mixed results that suggest a critical need for further investigation of the genetic factors and neuroadaptations that contribute to excessive ethanol intake.

Small-conductance $\mathrm{Ca}^{2+}$-activated $\mathrm{K}^{+}\left(\mathrm{K}_{\mathrm{ca}} 2\right.$ or $\left.\mathrm{SK}\right)$ channels have emerged from preclinical pharmacogenetic studies as a target for treating AUD $(6,10-14) . \mathrm{K}_{\mathrm{Ca}} 2.3$ channels are encoded by the KCNN3 gene and are enriched in nucleus accumbens core (NAcC) medium spiny neurons (MSNs) and substantia nigra dopamine neurons where they control neuronal firing patterns (15). In previous integrative functional genomics studies, we reported that cross-species ethanol-related QTLs contain KCNN3, and NAcC Kcnn3 transcript levels negatively correlated with voluntary drinking in genetically diverse BXD strains of mice $(13,14)$. Moreover, excessive differentiation in the promoter region of Kcnn3 associated with ethanol preference in selectively bred rat lines (16). Induction of ethanol dependence and excessive drinking increased intrinsic excitability and reduced $\mathrm{K}_{\mathrm{ca}} 2$ channel function and $\mathrm{K}_{\mathrm{ca}} 2.3$ channel protein expression in the $\mathrm{NAcC}$ of rodents $(11,13,17)$. Blocking $\mathrm{K}_{\mathrm{ca}} 2$ channels in the NAcC with apamin increased voluntary ethanol drinking in mice (13), whereas increasing $\mathrm{K}_{\mathrm{ca}} 2$ channel function with positive modulators reduced home cage drinking and operant self-administration (11, 17). Importantly, the ability of apamin to inhibit $\mathrm{K}_{\mathrm{ca}} 2$ channel function was completely lost in NAcC MSNs from ethanol 
dependent mice, but not in rats that had access to 7-weeks of operant self-administration of moderate amounts of ethanol (11). Together, these studies identified KCNN3 as a potential regulator of ethanol consumption and revealed NAcC neuroadaptations in $\mathrm{K}_{\mathrm{Ca}} 2$ channel function that may drive excessive drinking in preclinical rodent models of chronic ethanol exposure.

There are two polymorphic CAG repeats in the N-terminus of human KCNN3 encoded by exon 1 (18). Higher numbers of CAG repeats reduced $\mathrm{K}_{\mathrm{Ca}} 2$ channel function in transfected HEK293 cells (19), and this polymorphism has been associated with neuropsychiatric conditions, such as schizophrenia and anorexia nervosa (18, 20-23). While this polymorphism did not confer risk for developing the disease, longer CAG repeat length associated with higher cognitive performance in individuals with schizophrenia (19). This finding is consistent with a known role for $\mathrm{K}_{\mathrm{ca} 2} 2.3$ channel regulation of cognitive function and plasticity of intrinsic excitability that is an important mechanism for new learning to occur $(19,24,25)$. Because the CAG trinucleotide repeat is conserved in nonhuman primates $(19,24-26)$ and non-human primates exhibit a range of ethanol drinking that mimics human consumption (27-29), the present study explored the relationship between CAG repeat length and ethanol drinking in rhesus macaques with low- and high-drinking phenotypes.

DNA methylation (DNAm) is an epigenetic mark that can contribute to modulation of gene expression by modifying the compaction status of the chromatin. Alterations in DNA methylation are reported in heavy drinking monkeys and rodents (30-32), and a recent study demonstrated that knockdown of DNA methyltransferases reduced Kcnn3 expression and increased intrinsic excitability of cultured cortical neurons (33). Thus, we measured DNAm levels at a differentially methylated region (DMR) in exon 1 that coincides with a cross-species regulatory region within the KCNN3 promoter. In humans, the KCNN3 gene encodes four known transcript variants (TVs) by making use of alternative first exons and alternative splicing. Similar to the CAG trinucleotide repeat, alternative $K C N N 3$ TVs influence function of $\mathrm{K}_{\mathrm{Ca}} 2$ channels. KCNN3 variant SK3_1B encodes a truncated channel that functions as a dominant-negative to suppress endogenous $\mathrm{K}_{\mathrm{ca}} 2$ channel currents (34), whereas variant $h S K 3$ ex4 encodes a protein with an additional 15 amino acid insertion within the S5-PHelix loop that renders the channel insensitive to apamin block (35). We also determined if ethanol-induced changes in DNAm 
of exon 1 altered expression of KCNN3 TVs in the NACC of drinking mice and monkeys. Here, we report a complex cross-species relationship between NACC KCNN3 and excessive ethanol drinking that ultimately leads to reduced $\mathrm{K}_{\mathrm{Ca} 2} 2.3$ channel protein expression in mice and monkeys.

\section{Materials and methods}

\section{Ethanol self-administration in rhesus macaques}

Male and female rhesus macaques ( $n=66$, Macaca mulatta) from seven different cohorts (cohorts 4, 5, $6 a, 6 b, 7 a, 7 b$, and 10) were included in this study (Supplemental Table 1). All of the rhesus macaques were born and reared at the Oregon National Primate Research Center (ONPRC) with their mothers until 2-3 years of age. All subjects were initially selected to minimize relatedness; the average kinship coefficient of all subjects was 0.004 . The control subjects were selected by matching age and weight, and then kinship. Controls were housed in the same rooms as the experimental subjects and underwent the same training for awaken blood draws, medical check-ups, and MRI imaging. Controls experienced the same diet, timing and order of experimental phases and had equal experience with the research technicians. However, control monkeys did not have access to ethanol. Instead, controls were yoked to a future ethanol monkey based on weight, and received a quantity of $10 \%$ maltose-dextrin solution matched in calories to the previous day's intake of their yoked ethanol monkey. Monkeys were individually housed and ethanol self-administration was induced using schedule-induced polydipsia, as previously described (29). For all cohorts, monkeys had open access to $4 \%$ ethanol and water (ethanol subjects) or water only (control subjects) for 22 h/day for 12 months (see (28) for further details on these seven cohorts). It should be noted that the monkeys in cohort 10 had two cycles of forced abstinence and open access that followed the initial 12 months of open access. Because of the repeated abstinence, samples from monkeys in cohort 10 were limited to KCNN3 trinucleotide repeat analysis using blood collected prior to ethanol self-administration. While the technicians were not blind to the treatment condition (ethanol or control), the intake data were collected and recorded in an automated fashion by computer and analyzed by individuals who did not interact with or know the drinking status of the monkeys. All of the animal 
procedures used in this study were approved by the ONPRC IACUC and were performed in accordance with the $\mathrm{NIH}$ and the National Resource Council's Guide for the Care and Use of Laboratory Animals.

\section{Monkey Drinking Phenotypes}

The 49 monkeys with access to ethanol were classified into three different age categories based on their age of first ethanol access and four different drinking categories based on previously described criteria (27). There were 15 adolescent (4-5 years of age, $\sim 15-18$ human year equivalence; $n=6$ females), 24 young adult (5-6 years of age, $\sim 18-24$ human year equivalence; $n=5$ females), and 10 mature adult (7-11 years of age, $\sim 25-$

40 human year equivalence; $n=0$ females) monkeys. Monkeys were classified as very heavy drinking (VHD) if their average daily ethanol intake was $>3 \mathrm{~g} / \mathrm{kg}(\sim 12$ drink equivalent in humans) and they consumed $>4 \mathrm{~g} / \mathrm{kg}$ ethanol on $\geq 10 \%$ of their open access drinking days. Heavy drinking (HD) monkeys were defined as those that consumed $>3 \mathrm{~g} / \mathrm{kg}$ ethanol on $\geq 20 \%$ of their open access drinking days. Binge drinking (BD) monkeys were defined as those that consumed $>2 \mathrm{~g} / \mathrm{kg}$ ethanol on $\geq 55 \%$ of their open access drinking days. Low drinking (LD) monkeys were defined as those that did not reach these set thresholds for daily ethanol intake. Classification for cohort 10 was based on their drinking patterns after 12 months of open access. We have previously confirmed that the ethanol drinking behaviors did not reflect general differences in thirst (36).

\section{Ethanol dependence and two-bottle choice drinking in C57BL/6J mice}

Sixty adult male C57BL/6J mice were purchased from Jackson Laboratory (Bar Harbor, ME) at $\sim 7$ weeks of age. Mice were individually housed in a temperature and humidity controlled environment and kept on a $12 \mathrm{~h}$ light/dark cycle. Food and water were available ad libitum during all procedures. The Medical University of South Carolina Institutional Animal Care and Use Committee approved all procedures in accordance with $\mathrm{NIH}$ guidelines for the humane care and use of laboratory animals. To establish baseline drinking, half of the mice consumed ethanol in their home cage using a 2-bottle choice (15\% ethanol (v/v) vs. water) long-access (22 h) protocol for five weeks. Control mice consumed water in their home cage during this phase. Half of the control 
and ethanol drinking mice then underwent 4 repeated weekly cycles of chronic intermittent ethanol (CIE) exposure in vapor inhalation chambers, alternated with weekly home cage drinking sessions [2 (water vs ethanol drinking) $\times 2$ (air vs ethanol vapor inhalation) experimental design; $n=15$ mice/group] with $72 \mathrm{~h}$ in between $\mathrm{CIE}$ exposure and access to ethanol drinking bottles in their home cages. Ethanol vapor exposure was delivered in Plexiglas inhalation chambers as previously described (13). CIE treatment consists of sixteen hours of vapor exposure followed by eight $\mathrm{h}$ of withdrawal. Chamber ethanol concentrations were monitored daily and air flow was adjusted to maintain ethanol concentrations within a range that yields stable blood ethanol levels (175-225 $\mathrm{mg} / \mathrm{dl}$ ) throughout exposure. Prior to entry into the ethanol chambers, EtOH mice were administered ethanol (1.6 $\mathrm{g} / \mathrm{kg} ; 8 \% \mathrm{w} / \mathrm{v}$; i.p.; $20 \mathrm{ml} / \mathrm{kg}$ dose volume) and the alcohol dehydrogenase inhibitor pyrazole (1 mmol/kg). Control mice were handled similarly, but received injections of saline and pyrazole. Seventy-two h following the last vapor chamber exposure, mice were given limited access to ethanol or water for 2-3 days prior to sacrifice and tissue collection.

\section{Genomic DNA and total RNA isolation}

After the 12 month open access period, a detailed necropsy protocol was used to systematically collect tissues from all macaques (37). Monkeys were sedated with ketamine (15 mg/kg), and then the animals were brought into a surgical plane of anesthesia with intravenous administration of sodium pentobarbital (30-50 $\mathrm{mg} / \mathrm{kg}$, i.v.). Following extraction, the entire brain was blocked or sectioned into slices that were fresh frozen and stored at $-80^{\circ} \mathrm{C}$. The NAcC was later dissected from frozen brain slices. The typical postmortem interval for brain extractions was $<5$ minutes. Mouse brains were rapidly removed and placed in ice-cold saline before blocking 1-mm thick sections using a mouse brain block (ASI Instruments, Inc., Warren, MI, USA). A 1-mm tissue punch (Ted Pella, Inc., Redding, CA, USA) was used to extract the NAcC. Genomic DNA and RNA were extracted from male and female monkey and male mouse NAcC samples using the All Prep DNA/RNA/miRNA Universal kit (QIAGEN Sciences Inc, Germantown, MD) following the manufacturer's recommendations. Blood samples drawn from macaques prior to ethanol self-administration were used for CAG repeat analysis. Briefly, blood was 
collected in EDTA tubes and DNA was isolated using QIAamp DNA mini kit following manufacturer's instructions (QIAGEN Sciences Inc).

\section{Trinucleotide repeat analysis}

Blood DNA was used to analyze the number of CAG repeats within the second KCNN3 CAG repeat region as previously described (38). The primers (Forward: CAGCAGCCCCTGGGACCCTCG, Reverse: GGAGTTGGGCGAGCTGAGACAG) generated amplicons ranging between 112 bp and 178 bp, depending on the number of CAG repeats present. The PCR products were applied to an ABI3730 XL DNA Analyzer for separation and detection, incorporating a 600LIZ size standard with the PCR products at a 1:1 ratio (Applied Biosystems Inc.). The output files were visualized and product sizes were determined using Gene Mapper 4.0 software (Applied Biosystems Inc.). The sequence content of the amplification products was confirmed by PCR amplifying DNA from individuals with homozygous genotypes, and by direct DNA sequencing of PCR products. We found that the first exon 1 CAG repeat was not variable in rhesus macaques; thus, these studies focused on the second exon 1 CAG repeat length.

\section{Bisulfite amplicon sequencing}

Bisulfite amplicon sequencing was used to measure the DNAm rates of a DMR within the KCNN3 promoter region using NAcC tissue from macaques and mice. Correction for bisulfite-converted PCR bias was carried out as described by Moskalev et al. (39). Methylated and unmethylated human gDNAs (Zymo Research, Irvine, CA) were bisulfite-converted using the EZ DNA Methylation-Gold kit (Zymo Research, Irvine, CA), according to the manufacturer's instructions. The bisulfite converted DNAs were combined to create a series of methylation rate standards ranging from $100 \%$ to $0 \%$ methylated. gDNA (500ng) from rhesus and mouse NAcC was bisulfite converted following the same protocol. Primers were designed to amplify a 646bp region of the KCNN3 within exon $1 \mathrm{~A}$ and intron 1 in human, rhesus macaque and mice. Because of the length of the region, two sets of primers were designed to cover the whole region (Supplemental Table 2). Amplification was carried 
out in the C1000 Thermal Cycler (Bio-Rad, Hercules, CA) using 20 ng of bisulfite-treated DNA per PCR reaction. Amplification was carried out as follows: Phase 1: 10 cycles of $94^{\circ} \mathrm{C}$ for $30 \mathrm{sec} ., 68^{\circ} \mathrm{C}$ for $1 \mathrm{~min}$., with a touchdown decrease of $1^{\circ} \mathrm{C}$ per cycle. Phase 2: 28 cycles of $94^{\circ} \mathrm{C}$ for $30 \mathrm{sec}$. and $58^{\circ} \mathrm{C}$ for $45 \mathrm{sec}$. Libraries were prepared using the NETflex DNA Sequencing Kit (BIOO Scientific, Austin, TX) according to manufacturer's instructions. The libraries were evaluated using an Agilent 2100 Bioanalyzer (Agilent Technologies, Palo Alto, CA) and were normalized to $2 \mathrm{nM}$ with $10 \mathrm{mM}$ Tris- $\mathrm{HCl}$. The libraries were then pooled and sequenced on a MiSeq (Illumina, Inc. San Diego, CA) by the Molecular \& Cellular Biology Core, (ONPRC, Beaverton, OR) to generate 250-base paired-end reads. The reads were trimmed using Trim Galore and aligned to the corresponding reference genome $\quad$ (Rhesus: MacaM $\quad(40) \quad$ and $\quad$ Mouse: $\quad$ GRCm38.p3; https://www.ncbi.nlm.nih.gov/assembly/GCF_000001635.20/) using Bismark (41). M-bias plots were then generated (42), and reads were trimmed further as needed. Bismark alignment data was converted to CpG methylation rate using the Bismark methylation extractor (41) and custom scripts.

To assess the linearity of the PCR amplification we plotted the observed versus expected methylation rates obtained from the methylated DNA standard dilution series (39). Next, a hyperbolic function was applied to correct for PCR-bias obtaining a good linear fit $\left(r_{\text {Pair-1 }}^{2}=0.94 ; r_{\text {Pair-2 }}^{2}=0.94 ; r_{\text {Pair-3 }}^{2}=0.98\right.$; Supplemental Fig. 1).

\section{RNA isolation and reverse transcription}

The NAcC RNA quantity and quality was evaluated on a 2100 Bioanalyzer (Agilent Technologies, Santa Clara, CA). The Fluidigm Reverse Transcription Master Mix (Fluidigm, Inc., San Francisco, CA) was used to reverse-transcribe $100 \mathrm{ng}$ of each RNA sample following the manufacturer's instructions. Briefly, $1 \mu \mathrm{l}$ of $100 \mathrm{ng}$ of RNA was combined with $1 \mu$ of Reverse Transcription Master Mix and $3 \mu$ l of RNase-free water. The reactions were incubated at $25 \mathrm{C}$ for $2 \mathrm{~min}$, followed by $42 \mathrm{C}$ for $30 \mathrm{~min}$ and $85 \mathrm{C}$ for $5 \mathrm{~min}$. Next, $1.25 \mu \mathrm{l}$ of cDNA was pre-amplified using $1 \mu \mathrm{l}$ of PreAmp master mix, $0.5 \mu$ l of pooled primers (at $500 \mathrm{nM}$ ) and $2.25 \mu$ l of RNase-free water. The Pre-Amplification conditions were $95 \mathrm{C}$ for $2 \mathrm{~min}$, followed by 10 cycles at $95 \mathrm{C}$ for $15 \mathrm{~s}$ and $60 \mathrm{C}$ for $4 \mathrm{~min}$. To remove unincorporated primers, the reaction were mixed with $0.2 \mu$ l Exonuclease I reaction buffer, 0.4 
$\mu \mathrm{l}$ Exonuclease I (20 Units $/ \mathrm{ml}$ ) and $1.4 \mu \mathrm{l}$ of RNase-free water. The reactions were incubated at $37 \mathrm{C}$ for $30 \mathrm{~min}$ followed by $80 \mathrm{C}$ for $15 \mathrm{~min}$. The reactions were diluted (10x) with $43 \mu \mathrm{l}$ of TE buffer (TEKnova, Hollister, CA).

\section{High-throughput real time PCR}

qPCR was performed using the BioMark ${ }^{\text {TM }}$ HD System and the 96.96 GE Dynamic Arrays (Fluidigm, Inc., San Francisco, CA) in triplicates assays. $5 \mu \mathrm{L}$ of Fluidigm sample premix consisted of $2.25 \mu \mathrm{L}$ of $10 \mathrm{x}$ diluted preamplified cDNA, $0.25 \mu \mathrm{L}$ of 20x SG loading reagent (Fluidigm), $2.5 \mu \mathrm{L}$ of Sso Fast Eva Green Mastermix (BioRad). Each $5 \mu \mathrm{L}$ assay premix consisted of $0.25 \mu \mathrm{L}$ of $100 \mu \mathrm{M}$ primers (final concentration $500 \mathrm{nM}$ primers), 2.5 $\mu \mathrm{L} 2 \mathrm{x}$ Assay loading reagent (Fluidigm) and $2.25 \mu \mathrm{L}$ of $1 \mathrm{x}$ DNA suspension buffer (TEKnova, Hollister, CA). The samples and assays were mixed using the Nanoflex IFC controller (Fluidigm). Thermal qPCR conditions were: $95^{\circ} \mathrm{C}$ for $60 \mathrm{~s}, 35$ cycles of $95^{\circ} \mathrm{C}$ for $5 \mathrm{~s}$, and $60^{\circ} \mathrm{C}$ for $20 \mathrm{~s}$ plus melting curve analysis. Data was processed by automatic threshold for each assay, with derivative baseline correction using BioMark Real-Time PCR Analysis Software 3.1.2 (Fluidigm). The quality threshold was set at the default of 0.65 .

The primer sequences are described in Supplemental Table 3. Since most of the alternative transcript variants are not annotated in the Rhesus or mouse genome, we used the human annotations to design the primers, then identified the homologous sequence in the rhesus macaque (MacaM) (40) and mouse (GRCm38.p3) genome. The mRNA expression levels were normalized using the phosphoglycerate kinase (PGK1) gene. This gene was demonstrated to be a reliable control for brain gene expression (43). We also previously confirmed that different levels of ethanol use did not affect its expression (31). The monkeys 10171 (male) and 10068 (female) and mouse 16C control subjects were used as a reference sample for comparison.

\section{Western blot analysis}

After extraction, tissue samples containing the NAcC extracted from female control and long-term drinking rhesus macaques ( $n=5 /$ group) were snap frozen, shipped overnight on dry ice, and homogenized in 
$100 \mu \mathrm{l}$ of ice-cold homogenization buffer (50 mM Tris-HCl, $50 \mathrm{mM} \mathrm{NaCl}, 10 \mathrm{mM}$ EGTA, 5 mM EDTA; 2 mM sodium pyrophosphate, $1 \mathrm{mM}$ activated sodium orthovanadate, $0.2 \mathrm{mM}$ AEBSF, $1 \mu \mathrm{g} / \mathrm{ml}$ aprotinin, $1 \mathrm{mM}$ benzamide, $10 \mu \mathrm{g} / \mathrm{ml}$ leupeptin, $10 \mu \mathrm{g} / \mathrm{ml}$ pepstatin, $\mathrm{pH} 7.5)$. Samples were probe sonicated for $\sim 5 \mathrm{sec}$ and centrifuged at $23,100 \times \mathrm{g}$ for $30 \mathrm{~min}$ at $4^{\circ} \mathrm{C}$. The resulting supernatant was removed and the pellet was resuspended in $2 \%$ lauryl dodecyl sulfate (LDS) and probe sonicated for $\sim 5$ sec. An aliquot was taken for determination of protein concentration by the bicinchoninic acid assay (Pierce Biotechnology, Inc., Rockford, IL). Samples were diluted with NuPAGE 4X LDS sample loading buffer (Invitrogen Corp., Carlsbad, CA; pH 8.5) containing $50 \mathrm{mM}$ dithiothreitol, and samples were denatured for $10 \mathrm{~min}$ at $70^{\circ} \mathrm{C}$. We first performed a series of western blots using different titrations of sample and antibody to establish the linear range for $\mathrm{K}_{\mathrm{Ca}} 2.3$ (Alomone Labs, Jerusalem, Israel; Catalog \#: APC-025; epitope AA 2-21 of human $\mathrm{K}_{\mathrm{ca}} 2.3$ ) in primate tissue samples. Specificity of this antibody for $\mathrm{K}_{\mathrm{ca}} 2.3$ channels has been confirmed in conditional $\mathrm{K}_{\mathrm{ca}} 2.3$ knockout mice (44). Ten $\mu \mathrm{g}$ of each experimental sample was separated using the Bis-Tris (375 mM resolving buffer and 125 mM stacking buffer, pH 6.4; 7.5\% acrylamide) discontinuous buffer system with MOPS electrophoresis buffer (50 mM MOPS, $50 \mathrm{mM}$ Tris, 0.1\% SDS, $1 \mathrm{mM}$ EDTA, pH 7.7). Protein was then transferred to Immobilon-P PVDF membranes (Millipore, Bedford, MA) using a semi-dry transfer apparatus (Bio-Rad Laboratories, Hercules, CA). Blots were then washed with phosphate-buffered saline containing $0.1 \%$ Tween 20 (PBST) and blocked with PBST containing 5\% nonfat dried milk (NFDM) for $1 \mathrm{~h}$ at room temperature with agitation. The membranes were then incubated overnight at $4^{\circ} \mathrm{C}$ with primary antibody diluted $1: 4000$ in PBST containing $0.5 \%$ NFDM and washed in PBST prior to $1 \mathrm{~h}$ incubation at room temperature with horseradish peroxidase conjugated secondary antibody diluted 1:2000 in PBST. Membranes received a final wash in PBST and the antigen-antibody complex was detected by enhanced chemiluminescence using a ChemiDoc MP Imaging system (Bio-Rad Laboratories, Hercules, CA). The bands in the experimental samples were background subtracted and quantified by mean optical density using computer-assisted densitometry with Image Lab software (v4.0.1, Bio-Rad Laboratories) with the experimenter blind to the ethanol drinking groups. Because controls (e.g., actin, GAPDH) used to normalize protein loading in western blot experiments can cause quantitation errors (45-47), we used normalized to a total protein following our published methods in monkey tissue (48). 


\section{Statistical Analysis}

Data from heavy and very heavy drinking monkeys were combined due to small sample sizes in the transcript analysis and bisulfite sequencing studies. All statistical analyses were carried out using IBM SPSS Statistics (Armonk, NY) except where noted, with values $\alpha<0.05$. The Shapiro-Wilk test (appropriate for small sample sizes) was used to assess the normality of the average methylation rate, mRNA expression rate, and $\mathrm{K}_{\mathrm{Ca}} 2.3$ protein expression level per comparison group. All variables analyzed followed a normal distribution. Welch's one-way ANOVA was used to compare the difference in average methylation between controls and ethanol drinkers with Games-Howell post-hoc tests. One-way ANOVA was used to compare mRNA relative expression levels between groups. Prior to applying one-way ANOVA, Levene's test was used to test homogeneous variance assumption for parametric methods. When heterogeneous variance was detected, we used the nonparametric Kruskal-Wallis test. Bonferroni or Tukey correction for the multiple comparisons were used to correct the overall type I error rate. Two-tailed independent t-test was used to compare the difference in average methylation rate between controls and dependent mice. Based on the Levene's test for homogeneous variance, we used the appropriate p-value (homogeneous or heterogeneous variance). The allele frequency distribution of CAG trinucleotide repeats between controls and drinking monkeys was compared using the Kruskal-Wallis test (GraphPad Prism software, version 7.04, La Jolla, CA). Normalized western blot data were analyzed by a two-tailed t-test in Prism. Ethanol drinking data in mice were analyzed by a repeated-measures mixed linear model with a Tukey post-hoc test (SAS Institute, Cary, NC, USA).

\section{Results}

\section{Description of the animal ethanol drinking patterns}

Sixty-six unrelated, male and female rhesus macaques were used in this study. In addition to the 16 control monkeys, there were 16 LD, 9 BD, 9 HD, and 16 VHD monkeys. The average daily ethanol intake (range: 0.47 to $5.15 \mathrm{~g} / \mathrm{kg}$ ) across the 12 months of open access for each of the drinking monkeys along with their age at 
drinking onset and \% of drinking days over $3 \mathrm{~g} / \mathrm{kg}$ are shown in Fig. 1a. While the adolescent and young adult monkeys displayed a wide range of intake, only one of the mature adult monkeys used in this study met criteria for HD or VHD. More detailed analyses of their drinking patterns have been reported previously $(27,28)$.

To more closely match the monkey drinking paradigm, the standard two-bottle choice, limited-access mouse model of dependence-induced escalation of drinking was modified to allow mice to have access to ethanol $(15 \% \mathrm{v} / \mathrm{v})$ for $22 \mathrm{~h} /$ day. Ethanol drinking behavior prior to and following each weekly exposure to CIE is shown in Fig. 1b,c ( $n=15$ mice/group). Consistent with studies using limited access to ethanol $(13,49,50)$, mice exposed to CIE significantly increased their voluntary ethanol intake (interaction: $F(4,109)=2.47, p=0.0491$ ). Post hoc analysis indicated that the two treatment groups were not different at baseline $(p=0.6685)$, but differed during weekly test drinking sessions $1(p=0.0074), 2(p=0.0468)$, and $3(p=0.0034)$. In the ethanol dependent mice, drinking levels in all four test sessions were significantly higher than their intake during baseline $(p=$ $<0.0001)$

\section{KCNN3 methylation analysis}

By comparing the DNA sequence of the KCNN3 gene and promoter across human, rhesus macaque, and mouse, we identified ten regions with potential conserved regulatory region, based on sharing over 95\% sequence homology and $\geq 75 \%$ CpG identity. We then analyzed the DNAm patterns in these ten candidate regions between ethanol-naïve, $L D$, and HD/VHD rhesus macaques. Because of the small sample size, $B D$ were not included in this analysis, while HD and VHD were combined based on their similar drinking behavior. Among the different regions, only a region of 646 bp overlapping with exon 1 and intron 1 of KCNN3 (MR-ex1; Fig. 2a) showed significant DNAm differences between groups (Fig. 2b). The MR-ex1 region contained 24 CpGs in rhesus macaques that were 96\% conserved in humans (Supplemental Fig. 2). While the overall CpG conservation was lower in the mouse as compared to both human and rhesus macaques (15 CpGs, 75\%), the high sequence and CpG similarity of this region across species suggests functional relevance and underscores the potential translational value of the DNAm signal identified in this study. Overall, the CpGs within MR-ex1 
showed generally low DNAm in controls, with methylation levels ranging from 7-24\% in males (Fig. 2b) and 328\% in female macaques (Fig. 2c). In males, LD monkeys showed similar DNAm levels as controls; however, HD/VHD monkeys had increased methylation rates as compared to both controls and LD monkeys (Fig. 2b). In particular, nine CpGs had significantly higher methylation rates in male HD/VHD monkeys compared with control monkeys. In females, LD subjects could not be included in the analysis due to the small sample size (only 3 subjects). Nonetheless, and similar to heavy ethanol-drinking males, there were four CpGs with significantly higher methylation rates in the MR-ex1 region of VHD female macaques as compared to ethanol-naïve females

(Fig 2c).

Comparison of the MR-ex1 region to human ENCODE data (51) on 25 chromatin states for seven different brain areas predicted that this region coincides with promoter function (Supplemental Fig. 3). Furthermore, and in agreement with a potential role of this region as a promoter (52), several transcription factors relevant to neuronal regulation and known to have a role in mediating the effects of ethanol on gene regulation are predicted to bind to it, including GR (glucocorticoid receptor; (53)), ER-a (estrogen receptor; (54)), CREM (cAMP responsive element modulator; (55)), CREB (CAMP responsive element binding protein; (56)), Sp1 (57), GATA-3 (58), NeuroD1 (59), C/EBP (CCAAT-enhancer-binding proteins; (60)) and AP-2a (61) (Supplemental Fig. 4, TRANSFAC (62)). In addition to the fact that this methylation region is located in exon 1 (605 bp downstream of the transcription start site of exon $1 \mathrm{~A})$, it is upstream of exons $1 \mathrm{~B}$ and $1 \mathrm{C}(\sim 28 \mathrm{~kb}$ and $\sim 2 \mathrm{~kb}$; respectively), and could act as a regulatory region contributing to differential expression of $K C N N 3$ TVs.

We next investigated the methylation profile of the MR-ex1 region in mice that were drinking ethanol for $22 \mathrm{~h}$ in the CIE dependence model. Similar to ethanol-naïve rhesus macaques, this region was hypomethylated in air-exposed control mice. Kcnn3 methylation levels ranged from $0.1 \%$ to $17 \%$, with average methylation rates for 19 out of $21 \mathrm{CpGs}$ below 5\% in the controls. Interestingly, three CpGs showed significantly higher methylation rates in CIE-exposed drinking mice as compared to rates in the controls (Fig. 2d). These CpGs are conserved with rhesus macaques and humans (Supplemental Fig. 2) and two were located in the binding sites for AP-2a 
(Supplemental Fig. 4). Importantly, one CpG with predicted AP-2a, CREB, and GATA-3 binding sites was significantly differentially methylated in both female HD/VHD macaques and CIE-exposed mice.

\section{Expression of KCNN3 transcript variants differs with ethanol intake levels}

We next evaluated the potential relevance of MR-ex1 hypermethylation in regulating KCNN3 mRNA expression. The mouse (GRCm38.p3) and rhesus macaque (MacaM) genomes are not annotated with as much detail as the human. Thus, in order to investigate the effects of ethanol drinking on the expression of the different KCNN3 TVs, we designed primers to amplify two exons common to all reported TVs (SK3_ex7/8), as well as primers to specifically amplify TV SK3_ex4, SK3_ex1B, and SK3_ex1C in human. Next, each amplicon's orthologous sequence was identified in mouse and rhesus macaque, and species-specific primers for the different TVs were designed. It should be noted that TV SK3_ex1C was not detected in the NAcC, in agreement with previous studies indicating this TV is not expressed in the brain (63).

The expression of the exons common to all TVs (i.e., SK3_ex7/8) showed no differences among the different ethanol-drinking male monkey groups (one-way ANOVA: $F(2,23)=2.721, p=0.0870, n=8$-9/group; Fig. 3a). However, male monkeys with a HD/VHD phenotype showed a significant increase in expression of TV SK3_ex1B (one-way ANOVA: $F(2,22)=3.547, p=0.0462, n=7-10 /$ group) and SK3_ex4 (one-way ANOVA: $F(2,22)=9.89, p=0.0009, n=8$-9/group) that encode dominant-negative and apamin-insensitive isoforms of $\mathrm{K}_{\mathrm{Ca}} 2.3$ channels, respectively (Fig. 3b,c; Supplemental Table 4). In addition, TV SK3_ex4 was significantly increased in the accumbens of LD male monkeys (Fig. 3c). Since the male monkeys differed in their age of drinking onset, we wanted to determine if age is an important factor in ethanol regulation of KCNN3 transcript variant levels. Because of the lack of mature adult control monkeys, we could only include samples from adolescent and young adult male monkeys. In controls, expression of the TVs was not significantly different $(S K 3$ _ex7/8: two-tailed $t$-test; $t(2)=1.802, p=0.2134 ;$ SK3_ex1B: two-tailed $t$-test; $t(2)=0.1494, p=0.8950$; SK3_ex4: two-tailed $t$-test; $t(2)=0.6137, p=0.6019)$; thus, samples from these two age groups were pooled for further analysis. When collapsed across age, 12 months of open access to ethanol regardless of drinking 
phenotype significantly increased KCNN3 TV SK3_ex4 expression (one-way ANOVA: $F(2,17)=10.88, p=$ 0.0009; Fig. 3f), but not expression of the two other TVs $\left(S K 3 \_\right.$ex7/8: one-way ANOVA: $F(2,18)=1.798, p=$ 0.1941; SK3_ex1B: one-way ANOVA: $F(2,17)=2.935 ; p=0.0803 ;$ Fig. 3d,e), in adolescent and young adult male monkeys.

Because KCNN3 is hypermethylated in HD/VHD monkeys and transcriptionally regulated by estrogen (64), analysis of KCNN3 TVs was also performed in control and ethanol-drinking female monkeys. Similar to the male monkeys, KCNN3 TV SK3_ex7/8 expression did not differ between the control and VHD female monkeys

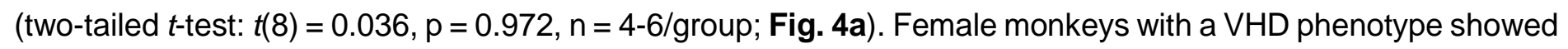
a significant increase in expression of TV SK3_ex1B (two-tailed $t$-test: $t(10)=2.658, p=0.024, n=5-7 / g r o u p$; Fig. 4b) and SK3_ex4 (two-tailed t-test: $t(9)=2.477, \mathrm{p}=0.037, \mathrm{n}=5$-6/group; Fig. 4c). All females were of similar age (i.e., 4 - 6 years old at the start of induction), and no age effect on gene expression was performed. To determine if hypermethylation of $K C N N 3$ and the shifts in TV expression affected $\mathrm{K}_{\mathrm{Ca}} 2.3$ channel protein expression, we performed western blot analysis in accumbens from the same female rhesus macaques. Characterization of $\mathrm{K}_{\mathrm{ca}} 2.3$ channel immunoreactivity in ethanol-naïve monkey accumbens samples revealed a linear dynamic range across twofold dilutions between 1.25 and $40 \mu \mathrm{g}$ of protein $\left(R^{2}=0.9963\right.$; Fig. $4 \mathbf{d}$,e). Consistent with results from rodent ethanol studies $(11,13,17)$, expression of $\mathrm{K}_{\mathrm{ca}} 2.3$ channel protein was significantly reduced in VHD female monkeys compared with controls (two-tailed $t$-test: $t(8)=2.585, p=0.0324$, $n=5 /$ group; Fig. 4f,g). Unfortunately, our attempts to detect the different isoforms of $\mathrm{K}_{\mathrm{ca}} 2.3$ channel, such as the dominant-negative isoform 3 with a predicted molecular weight of $47 \mathrm{kDa}$, were unsuccessful with commercially available antibodies.

Given that chronic ethanol drinking and dependence reduced $\mathrm{K}_{\mathrm{ca}} 2$ currents and expression in the accumbens of rats and mice $(11,13,17)$, we next determined if Kcnn3 TV expression is altered in ethanol dependent mice. Similar to the monkey data, ethanol drinking and/or dependence did not affect Kcnn3 expression of SK3_ex7/8 (two-way ANOVA: main effect: $F(1,50)=3.931, p=0.0529$; Fig. $\mathbf{3 g}$ ). In contrast, dependent mice with access to ethanol in their home cage showed elevated SK3_ex1B expression (two-way ANOVA: interaction: $F(1,31)=7.228, p=0.0114$; Fig. 3h). Expression of SK3_ex4 was significantly increased 
in drinking mice regardless of their history of CIE exposure (two-way ANOVA: $F(1,44)=32.29, p<0.0001$; Fig. 3i).

\section{KCNN3 polymorphisms and ethanol consumption levels}

In addition to DNAm as a potential regulator of KCNN3 expression, MR-ex1 contains two polymorphic sites in the promoter region of the KCNN3 gene that are composed of a variable number of CAG repeats and have been associated with $\mathrm{K}_{\mathrm{Ca}} 2$ channel activity. It has been reported higher numbers of CAG repeats reduces $\mathrm{K}_{\mathrm{Ca}} 2$ channel currents (19). We then investigated the presence of these polymorphic sites in ethanol-drinking rhesus macaques and whether they would influence KCNN3 regulation. In contrast to the first CAG repeat array that was not polymorphic, the second CAG repeat array was highly polymorphic across rhesus monkeys (Fig. 5a) and ranged from seven to 30 repeats. We found no differences between the frequency distributions for CAG repeats in low, binge, high and very high drinking monkeys $(H(4)=2.354, p=0.5023$; Fig. 5a). In addition, the sum of CAG repeats of both alleles did not correlate with ethanol intake values $(p=0.6946$; Fig. 5b), the expression of KCNN3 variants ( $p \geq 0.1631$; Fig. 5c-e), nor averaged MR-ex1 DNAm rates $(p=0.3563$;

\section{Supplemental Fig. 5).}

\section{DISCUSSION}

The results from these studies provide cross-species evidence for epigenetic regulation of accumbens KCNN3 expression in heavy drinking macaques and ethanol dependent mice. In both monkeys and mice, ethanol drinking and dependence was associated with hypermethylation of conserved CpGs at a predicted regulatory region in exon $1 \mathrm{~A}$ of $K C N N 3$. In parallel with the hypermethylation, excessive drinking increased expression of a dominant-negative transcript variant of $K C N N 3$ that is transcribed using an alternative exon downstream of exon 1A. Consistent with chronic ethanol-induced loss of apamin-sensitive currents in accumbens and orbitofrontal neurons $(11,13,65)$, ethanol drinking increased expression of the transcript variant that encodes apamin-insensitive $\mathrm{K}_{\mathrm{ca}} 2$ channels. We also found a reduction in $\mathrm{K}_{\mathrm{ca}} 2.3$ channel protein in heavy 
drinking female macaques that is congruent with decreased expression reported in rodent models of chronic ethanol exposure. These results suggest that ethanol-induced regulation of $K C N N 3$ transcript variants is a conserved mechanism that underlies functional changes in $\mathrm{K}_{\mathrm{ca}} 2$ channels reported in rodent models.

In the current study, we identified a DMR that maps to an ion channel gene previously implicated in excessive drinking, ethanol-seeking behaviors, and ethanol-induced plasticity of intrinsic excitability $(6,10,11$, $13,17)$. Our analysis identified a DMR that spans exon 1 and part of intron 1 of monkey and mouse KCNN3 in a region containing CpGs that are highly conserved across species. Across male and female monkeys, more than half of the CpGs in this DMR were hypermethylated in HD/VHD, but not in LD or ethanol-naïve monkeys, an effect that is also conserved in ethanol dependent mice that show escalated drinking. Importantly, the DMR in exon 1 of $K C N N 3$ coincides with a predicted promoter region with transcription binding sites for neural relevant transcription factors. Furthermore, this DMR is upstream of two alternative exons 1 (1B and $1 C$ ). All together, these findings suggest that the DMR is strategically located to potentially regulate alternative transcript expression of $K C N N 3$. A previous characterization of the promoter region upstream of the exon $1 \mathrm{~A}$ transcription start site (TSS) identified consensus sequence binding sites for CREB, AP-1, and AP-2 (52). Additional binding sites for these same transcription factors are predicted to bind to MR-ex1, specifically to significantly differentially methylated CpGs. Numerous signaling transduction pathways that are altered by ethanol consumption lead to CREB activation (66), a key mediator in the development of addiction. Upon activation, CREB can exert its influence upon target gene transcription and interact with promoter-bound cofactors. Previous evidence showed that CREB modulates BK channel expression (67), and our results suggest that it may also modulate $K C N N 3$ expression. AP-1 complexes containing FosB, which accumulates in the NAc after drug intake, modulates promoters of genes relevant to addiction, such as GluA2 and dynorphin (68). The MR-ex1 region also contains binding sites for glucocorticoids, which have been extensively associated with AUD $(69,70)$. Others have shown that glucocorticoids and stress exert profound effects on intrinsic excitability in neurons through regulation of ion channel activity, including $\mathrm{K}_{\mathrm{ca}} 2$ channels (71-74). Thus, it is possible that ethanol, by modulating transcription factor levels as well as availability of binding sites by DNAm, modulates KCNN3 expression. Using a genomewide approach, we previously reported DMRs associated with the modulation of genes that regulate synaptic 
plasticity in the NACC of heavy drinking monkeys (31). In a recent analysis of the NAcC methylome of ethanolnaïve and HD/VHD macaques, we identified the same DMR described in this study (unpublished data). Furthermore, induction of ethanol dependence in C57BL/6J mice increased evoked firing in NAcC MSNs (13) and induced synaptic proteome adaptations in the NACC (75). Because alterations in neuronal firing underlie synaptic integration and learning processes and may facilitate drug-associated synaptic remodeling $(76,77)$, our findings suggest that a change in the methylation status of key CpGs is a critical cross-species mechanism that regulates possible coordinated neuronal excitability and synaptic adaptations in heavy drinking animals.

In monkeys and mice, heavy ethanol drinking and dependence increased expression of $K C N N 3$ transcript variants that encode $\mathrm{K}_{\mathrm{ca}} 2.3$ channels that reduce surface trafficking and apamin sensitivity. A combination of TV and protein expression data suggest that heavy ethanol consumption results in a decrease in TV SK3_ex1A expression while there is an upregulation in TVs SK3_ex1B and SK3_ex4. While expression of the dominantnegative TV was only increased in heavy drinking monkey, expression of the apamin-insensitive TV was increased by ethanol intake regardless of the drinking phenotype or the age of drinking onset. These results are in agreement with our functional and behavioral data on reduced apamin sensitivity in the nucleus accumbens and orbitofrontal cortex of ethanol dependent mice and self-administering rats $(11,13,65)$. We previously reported that apamin microinfusion into the NAcC increased drinking and bath application of apamin reduced $\mathrm{K}_{\mathrm{Ca}} 2-$ mediated currents in NAcC MSNs in non-dependent C57BL/6J mice. However, the ability of apamin to influence drinking and $\mathrm{K}_{\mathrm{ca}} 2$ currents was completely lost when mice were exposed to CIE. Moreover, ethanol intake and evoked firing in NAcC MSNs were increased and there was a reduction in $\mathrm{K}_{\mathrm{ca}} 2$ channel currents and protein in the ethanol dependent mice. Although it is unknown if heavy ethanol drinking in macaques alters firing properties of NAcC MSNs, the shift in transcript variants and the reduction in total $\mathrm{K}_{\mathrm{ca}} 2$ channel protein suggests that prolonged ethanol intake will increase intrinsic excitability similar to results from rodent models of ethanol self-administration $(11)$ and dependence $(13,78)$. In addition to reduced Kcnn3 gene expression and increased intrinsic excitability, a recent study reported a loss of apamin's ability to increase evoked firing in cultured cortical neurons treated with DNA methyltransferase inhibitors (33). Thus, these data provide support that the increase 
in SK3_ex1B and SK3_ex4 TV expression through hypermethylation of KCNN3 exon $1 \mathrm{~A}$ is an underlying mechanism driving these functional and behavioral adaptations across species and brain regions.

Previous studies using functional genomics and rodents with divergent drinking phenotypes have identified Kcnn3 as a candidate signature gene that is associated with binge-like and excessive ethanol drinking $(6,9,13,14,16)$. In contrast to this mounting evidence and our hypothesis, high numbers of polymorphic trinucleotide repeats encoded by exon 1 of $K C N N 3$ did not segregate with a heavy drinking phenotype in this population of rhesus macaques. There are a number of possibilities that could explain these negative findings. Although long CAG repeats in $\mathrm{K}_{\mathrm{Ca}} 2.3$ channels reduced apamin-sensitive currents (19), function of this polymorphism was characterized in transfected HEK293 cells and not mammalian central neurons. In the current study, CAG repeat number was measured from blood samples taken after chronic ethanol consumption. While traditionally considered stable, there is some evidence that CAG repeats can vary between types of tissue (i.e, peripheral vs central) and can expand across time to accelerate disease progression (79, 80). Thus, future longitudinal studies are necessary to track CAG repeat number in the NAcC of LD and HD/VHD monkeys.

In summary, these cross-species findings on genetic and epigenetic adaptations in KCNN3 by excessive alcohol consumption represent a complex mechanism through the use of alternative promoters that likely impact intrinsic excitability of NACC MSNs, and, ultimately, ethanol-seeking behaviors. We propose a model in which MR-ex1 functions as a regulatory region to modulate the expression of the alternative transcript variants SK3_ex1B and SK3_ex4. Our findings provide the first evidence that hypermethylation of the MR-ex1 region of KCNN3 by heavy alcohol drinking is a key cross-species mechanism that may be important for the maintenance of excessive drinking and the development of AUD. 


\section{ACKNOWLEDGEMENTS}

The authors would like to acknowledge the support of the Monkey Alcohol Tissue Research Resource (NIH grant AA019431 (KAG)) and Drs. Erich Baker and James Daunais for their assistance with the monkey drinking data and monkey brain samples, respectively. This work was supported by NIH grants AA020930 (PJM), AA013641 (KAG), AA013510 (KAG), AA026092 (RCJ), and AA020928 (BMF).

\section{CONFLICT OF INTEREST}

The authors do not have any conflicts of interest to report. 


\section{References}

1. Sacks JJ, Gonzales KR, Bouchery EE, Tomedi LE, Brewer RD. 2010 National and State Costs of Excessive Alcohol Consumption. Am J Prev Med. 2015;49(5):e73-e9.

2. Stahre M, Roeber J, Kanny D, Brewer RD, Zhang X. Contribution of excessive alcohol consumption to deaths and years of potential life lost in the United States. Prev Chronic Dis. 2014;11:E109.

3. Schuckit MA. A Critical Review of Methods and Results in the Search for Genetic Contributors to Alcohol Sensitivity. Alcohol Clin Exp Res. 2018;42(5):822-35.

4. Reilly MT, Noronha A, Goldman D, Koob GF. Genetic studies of alcohol dependence in the context of the addiction cycle. Neuropharmacology. 2017;122:3-21.

5. Cservenka A, Yardley MM, Ray LA. Review: Pharmacogenetics of alcoholism treatment: Implications of ethnic diversity. Am J Addict. 2017;26(5):516-25.

6. Cannady R, Rinker JA, Nimitvilai S, Woodward JJ, Mulholland PJ. Chronic Alcohol, Intrinsic Excitability, and Potassium Channels: Neuroadaptations and Drinking Behavior. Handb Exp Pharmacol. 2018.

7. Mulholland PJ, Chandler LJ, Kalivas PW. Signals from the Fourth Dimension Regulate Drug Relapse. Trends Neurosci. 2016;39(7):472-85.

8. Ron D, Barak S. Molecular mechanisms underlying alcohol-drinking behaviours. Nat Rev Neurosci. 2016;17(9):576-91.

9. Rinker JA, Mulholland PJ. Promising pharmacogenetic targets for treating alcohol use disorder: evidence from preclinical models. Pharmacogenomics. 2017;18(6):555-70.

10. Cannady R, McGonigal JT, Newsom RJ, Woodward JJ, Mulholland PJ, Gass JT. Prefrontal Cortex KCa2 Channels Regulate mGlu5-Dependent Plasticity and Extinction of Alcohol-Seeking Behavior. J Neurosci. 2017;37(16):4359-69.

11. Hopf FW, Bowers MS, Chang SJ, Chen BT, Martin M, Seif T, et al. Reduced Nucleus Accumbens SK Channel Activity Enhances Alcohol Seeking during Abstinence. Neuron. 2010;65(5):682-94.

12. Mulholland PJ, Hopf FW, Bukiya AN, Martin GE, Liu J, Dopico AM, et al. Sizing up ethanol-induced plasticity: the role of small and large conductance calcium-activated potassium channels. Alcohol Clin Exp Res. 2009;33(7):1125-35.

13. Padula AE, Griffin WC, 3rd, Lopez MF, Nimitvilai S, Cannady R, McGuier NS, et al. KCNN Genes that Encode Small-Conductance Ca2+-Activated $\mathrm{K}+$ Channels Influence Alcohol and Drug Addiction. Neuropsychopharmacology. 2015;40(8):1928-39.

14. Rinker JA, Fulmer DB, Trantham-Davidson $\mathrm{H}$, Smith ML, Williams RW, Lopez MF, et al. Differential potassium channel gene regulation in BXD mice reveals novel targets for pharmacogenetic therapies to reduce heavy alcohol drinking. Alcohol. 2017;58:33-45.

15. Wolfart J, Neuhoff $\mathrm{H}$, Franz O, Roeper J. Differential expression of the small-conductance, calciumactivated potassium channel SK3 is critical for pacemaker control in dopaminergic midbrain neurons. J Neurosci. 2001;21(10):3443-56.

16. Lo CL, Lossie AC, Liang T, Liu Y, Xuei X, Lumeng L, et al. High Resolution Genomic Scans Reveal Genetic Architecture Controlling Alcohol Preference in Bidirectionally Selected Rat Model. PLoS Genet. 2016;12(8):e1006178. 
17. Hopf FW, Simms JA, Chang SJ, Seif T, Bartlett SE, Bonci A. Chlorzoxazone, an SK-type potassium channel activator used in humans, reduces excessive alcohol intake in rats. Biological psychiatry. 2011;69(7):618-24.

18. Chandy KG, Fantino E, Wittekindt O, Kalman K, Tong LL, Ho TH, et al. Isolation of a novel potassium channel gene hSKCa3 containing a polymorphic CAG repeat: a candidate for schizophrenia and bipolar disorder? Mol Psychiatry. 1998;3(1):32-7.

19. Grube S, Gerchen MF, Adamcio B, Pardo LA, Martin S, Malzahn D, et al. A CAG repeat polymorphism of KCNN3 predicts SK3 channel function and cognitive performance in schizophrenia. EMBO Mol Med. 2011;3(6):309-19.

20. Cardno AG, Bowen T, Guy CA, Jones LA, McCarthy G, Williams NM, et al. CAG repeat length in the hKCa3 gene and symptom dimensions in schizophrenia. Biol Psychiatry. 1999;45(12):1592-6.

21. Glatt SJ, Faraone SV, Tsuang MT. CAG-repeat length in exon 1 of KCNN3 does not influence risk for schizophrenia or bipolar disorder: a meta-analysis of association studies. American journal of medical genetics Part B, Neuropsychiatric genetics : the official publication of the International Society of Psychiatric Genetics. 2003;121B(1):14-20.

22. Koronyo-Hamaoui M, Danziger Y, Frisch A, Stein D, Leor S, Laufer N, et al. Association between anorexia nervosa and the hsKCa3 gene: a family-based and case control study. Mol Psychiatry. 2002;7(1):82-5.

23. Koronyo-Hamaoui M, Frisch A, Stein D, Denziger Y, Leor S, Michaelovsky E, et al. Dual contribution of NR2B subunit of NMDA receptor and SK3 $\mathrm{Ca}(2+)$-activated $\mathrm{K}+$ channel to genetic predisposition to anorexia nervosa. J Psychiatr Res. 2007;41(1-2):160-7.

24. Blank T, Nijholt I, Kye MJ, Radulovic J, Spiess J. Small-conductance, Ca2+-activated K+ channel SK3 generates age-related memory and LTP deficits. Nat Neurosci. 2003;6(9):911-2.

25. Jacobsen JP, Redrobe JP, Hansen HH, Petersen S, Bond CT, Adelman JP, et al. Selective cognitive deficits and reduced hippocampal brain-derived neurotrophic factor mRNA expression in small-conductance calcium-activated K+ channel deficient mice. Neuroscience. 2009;163(1):73-81.

26. Andres AM, Soldevila M, Lao O, Volpini V, Saitou N, Jacobs HT, et al. Comparative genetics of functional trinucleotide tandem repeats in humans and apes. Journal of molecular evolution. 2004;59(3):329-39.

27. Baker EJ, Farro J, Gonzales S, Helms C, Grant KA. Chronic alcohol self-administration in monkeys shows long-term quantity/frequency categorical stability. Alcohol Clin Exp Res. 2014;38(11):2835-43.

28. Baker EJ, Walter NA, Salo A, Rivas Perea P, Moore S, Gonzales S, et al. Identifying Future Drinkers: Behavioral Analysis of Monkeys Initiating Drinking to Intoxication is Predictive of Future Drinking Classification. Alcohol Clin Exp Res. 2017;41(3):626-36.

29. Grant KA, Leng X, Green HL, Szeliga KT, Rogers LS, Gonzales SW. Drinking typography established by scheduled induction predicts chronic heavy drinking in a monkey model of ethanol self-administration. Alcohol Clin Exp Res. 2008;32(10):1824-38.

30. Barbier E, Tapocik JD, Juergens N, Pitcairn C, Borich A, Schank JR, et al. DNA methylation in the medial prefrontal cortex regulates alcohol-induced behavior and plasticity. J Neurosci. 2015;35(15):6153-64.

31. Cervera-Juanes R, Wilhelm LJ, Park B, Grant KA, Ferguson B. Alcohol-dose-dependent DNA methylation and expression in the nucleus accumbens identifies coordinated regulation of synaptic genes. Translational psychiatry. 2017;7(1):e994. 
32. Cervera-Juanes R, Wilhelm LJ, Park B, Grant KA, Ferguson B. Genome-wide analysis of the nucleus accumbens identifies DNA methylation signals differentiating low/binge from heavy alcohol drinking. Alcohol. 2017;60:103-13.

33. Meadows JP, Guzman-Karlsson MC, Phillips S, Brown JA, Strange SK, Sweatt JD, et al. Dynamic DNA methylation regulates neuronal intrinsic membrane excitability. Sci Signal. 2016;9(442):ra83.

34. Tomita H, Shakkottai VG, Gutman GA, Sun G, Bunney WE, Cahalan MD, et al. Novel truncated isoform of SK3 potassium channel is a potent dominant-negative regulator of SK currents: implications in schizophrenia. Molecular psychiatry. 2003;8(5):524-35, 460.

35. Wittekindt $\mathrm{OH}$, Visan V, Tomita H, Imtiaz F, Gargus JJ, Lehmann-Horn F, et al. An apamin- and scyllatoxin-insensitive isoform of the human SK3 channel. Mol Pharmacol. 2004;65(3):788-801.

36. Cervera-Juanes R, Wilhem LJ, Park B, Lee R, Locke J, Helms C, et al. MAOA expression predicts vulnerability for alcohol use. Mol Psychiatry. 2016;21(4):472-9.

37. Davenport AT, Grant KA, Szeliga KT, Friedman DP, Daunais JB. Standardized method for the harvest of nonhuman primate tissue optimized for multiple modes of analyses. Cell Tissue Bank. 2014;15(1):99-110.

38. Curtain R, Sundholm J, Lea R, Ovcaric M, MacMillan J, Griffiths L. Association analysis of a highly polymorphic CAG Repeat in the human potassium channel gene KCNN3 and migraine susceptibility. BMC medical genetics. 2005;6:32.

39. Moskalev EA, Zavgorodnij MG, Majorova SP, Vorobjev IA, Jandaghi P, Bure IV, et al. Correction of PCRbias in quantitative DNA methylation studies by means of cubic polynomial regression. Nucleic acids research. 2011;39(11):e77.

40. Zimin AV, Cornish AS, Maudhoo MD, Gibbs RM, Zhang X, Pandey S, et al. A new rhesus macaque assembly and annotation for next-generation sequencing analyses. Biol Direct. 2014;9(1):20.

41. Krueger F, Andrews SR. Bismark: a flexible aligner and methylation caller for Bisulfite-Seq applications. Bioinformatics. 2011;27(11):1571-2.

42. Hansen KD, Langmead B, Irizarry RA. BSmooth: from whole genome bisulfite sequencing reads to differentially methylated regions. Genome Biol. 2012;13(10):R83.

43. Boda E, Pini A, Hoxha E, Parolisi R, Tempia F. Selection of reference genes for quantitative real-time RT-PCR studies in mouse brain. J Mol Neurosci. 2009;37(3):238-53.

44. Bond CT, Herson PS, Strassmaier T, Hammond R, Stackman R, Maylie J, et al. Small conductance $\mathrm{Ca} 2+$-activated $\mathrm{K}+$ channel knock-out mice reveal the identity of calcium-dependent afterhyperpolarization currents. J Neurosci. 2004;24(23):5301-6.

45. Aldridge GM, Podrebarac DM, Greenough WT, Weiler IJ. The use of total protein stains as loading controls: an alternative to high-abundance single-protein controls in semi-quantitative immunoblotting. $\mathrm{J}$ Neurosci Methods. 2008;172(2):250-4.

46. Dittmer A, Dittmer J. Beta-actin is not a reliable loading control in Western blot analysis. Electrophoresis. 2006;27(14):2844-5.

47. Welinder C, Ekblad L. Coomassie staining as loading control in Western blot analysis. Journal of proteome research. 2011;10(3):1416-9. 
48. Nimitvilai S, Uys JD, Woodward JJ, Randall PK, Ball LE, Williams RW, et al. Orbitofrontal Neuroadaptations and Cross-Species Synaptic Biomarkers in Heavy-Drinking Macaques. J Neurosci. 2017;37(13):3646-60.

49. Becker HC, Lopez MF. Increased ethanol drinking after repeated chronic ethanol exposure and withdrawal experience in C57BL/6 mice. Alcohol Clin Exp Res. 2004;28(12):1829-38.

50. Lopez MF, Becker HC. Effect of pattern and number of chronic ethanol exposures on subsequent voluntary ethanol intake in C57BL/6J mice. Psychopharmacology (Berl). 2005;181(4):688-96.

51. Consortium EP. An integrated encyclopedia of DNA elements in the human genome. Nature. 2012;489(7414):57-74.

52. Sun G, Tomita H, Shakkottai VG, Gargus JJ. Genomic organization and promoter analysis of human KCNN3 gene. J Hum Genet. 2001;46(8):463-70.

53. Vendruscolo LF, Estey D, Goodell V, Macshane LG, Logrip ML, Schlosburg JE, et al. Glucocorticoid receptor antagonism decreases alcohol seeking in alcohol-dependent individuals. J Clin Invest. 2015;125(8):3193-7.

54. Vandegrift BJ, You C, Satta R, Brodie MS, Lasek AW. Estradiol increases the sensitivity of ventral tegmental area dopamine neurons to dopamine and ethanol. PloS one. 2017;12(11):e0187698.

55. Mellstrom B, Naranjo JR, Foulkes NS, Lafarga M, Sassone-Corsi P. Transcriptional response to cAMP in brain: specific distribution and induction of CREM antagonists. Neuron. 1993;10(4):655-65.

56. Wand G. The anxious amygdala: CREB signaling and predisposition to anxiety and alcoholism. J Clin Invest. 2005;115(10):2697-9.

57. Rulten SL, Ripley TL, Hunt CL, Stephens DN, Mayne LV. Sp1 and NFkappaB pathways are regulated in brain in response to acute and chronic ethanol. Genes Brain Behav. 2006;5(3):257-73.

58. Zhao GY, Li ZY, Zou HL, Hu ZL, Song NN, Zheng MH, et al. Expression of the transcription factor GATA3 in the postnatal mouse central nervous system. Neurosci Res. 2008;61(4):420-8.

59. Taffe MA, Kotzebue RW, Crean RD, Crawford EF, Edwards S, Mandyam CD. Long-lasting reduction in hippocampal neurogenesis by alcohol consumption in adolescent nonhuman primates. Proc Natl Acad Sci U S A. 2010;107(24):11104-9.

60. Chen A, Muzzio IA, Malleret G, Bartsch D, Verbitsky M, Pavlidis P, et al. Inducible enhancement of memory storage and synaptic plasticity in transgenic mice expressing an inhibitor of ATF4 (CREB-2) and C/EBP proteins. Neuron. 2003;39(4):655-69.

61. Covarrubias MY, Khan RL, Vadigepalli R, Hoek JB, Schwaber JS. Chronic alcohol exposure alters transcription broadly in a key integrative brain nucleus for homeostasis: the nucleus tractus solitarius. Physiol Genomics. 2005;24(1):45-58.

62. Matys V, Kel-Margoulis OV, Fricke E, Liebich I, Land S, Barre-Dirrie A, et al. TRANSFAC and its module TRANSCompel: transcriptional gene regulation in eukaryotes. Nucleic acids research. 2006;34(Database issue):D108-10.

63. Kolski-Andreaco A, Tomita H, Shakkottai VG, Gutman GA, Cahalan MD, Gargus JJ, et al. SK3-1C, a dominant-negative suppressor of SKCa and IKCa channels. J Biol Chem. 2004;279(8):6893-904. 
64. Jacobson D, Pribnow D, Herson PS, Maylie J, Adelman JP. Determinants contributing to estrogenregulated expression of SK3. Biochemical and biophysical research communications. 2003;303(2):660-8.

65. Nimitvilai S, Lopez MF, Mulholland PJ, Woodward JJ. Chronic Intermittent Ethanol Exposure Enhances the Excitability and Synaptic Plasticity of Lateral Orbitofrontal Cortex Neurons and Induces a Tolerance to the Acute Inhibitory Actions of Ethanol. Neuropsychopharmacology. 2016;41(4):1112-27.

66. McPherson CS, Lawrence AJ. The nuclear transcription factor CREB: involvement in addiction, deletion models and looking forward. Curr Neuropharmacol. 2007;5(3):202-12.

67. Ghezzi A, Pohl JB, Wang Y, Atkinson NS. BK channels play a counter-adaptive role in drug tolerance and dependence. Proc Natl Acad Sci U S A. 2010;107(37):16360-5.

68. Nestler EJ. Review. Transcriptional mechanisms of addiction: role of DeltaFosB. Philos Trans R Soc Lond B Biol Sci. 2008;363(1507):3245-55.

69. Prendergast MA, Mulholland PJ. Glucocorticoid and polyamine interactions in the plasticity of glutamatergic synapses that contribute to ethanol-associated dependence and neuronal injury. Addict Biol. 2012;17(2):209-23.

70. Rose AK, Shaw SG, Prendergast MA, Little HJ. The importance of glucocorticoids in alcohol dependence and neurotoxicity. Alcohol Clin Exp Res. 2010;34(12):2011-8.

71. Prouty EW, Chandler DJ, Gao WJ, Waterhouse BD. Selective vulnerability of dorsal raphe-medial prefrontal cortex projection neurons to corticosterone-induced hypofunction. Eur J Neurosci. 2019.

72. Kerr DS, Campbell LW, Hao SY, Landfield PW. Corticosteroid modulation of hippocampal potentials: increased effect with aging. Science. 1989;245(4925):1505-9.

73. Joels $\mathrm{M}$, de Kloet ER. Effects of glucocorticoids and norepinephrine on the excitability in the hippocampus. Science. 1989;245(4925):1502-5.

74. Rau AR, Chappell AM, Butler TR, Ariwodola OJ, Weiner JL. Increased Basolateral Amygdala Pyramidal Cell Excitability May Contribute to the Anxiogenic Phenotype Induced by Chronic Early-Life Stress. J Neurosci. 2015;35(26):9730-40.

75. Uys JD, McGuier NS, Gass JT, Griffin WC, 3rd, Ball LE, Mulholland PJ. Chronic intermittent ethanol exposure and withdrawal leads to adaptations in nucleus accumbens core postsynaptic density proteome and dendritic spines. Addict Biol. 2015.

76. Kourrich S, Calu DJ, Bonci A. Intrinsic plasticity: an emerging player in addiction. Nat Rev Neurosci. 2015;16(3):173-84.

77. Sehgal M, Song C, Ehlers VL, Moyer JR, Jr. Learning to learn - intrinsic plasticity as a metaplasticity mechanism for memory formation. Neurobiol Learn Mem. 2013;105:186-99.

78. Renteria R, Maier EY, Buske TR, Morrisett RA. Selective alterations of NMDAR function and plasticity in D1 and D2 medium spiny neurons in the nucleus accumbens shell following chronic intermittent ethanol exposure. Neuropharmacology. 2017;112(Pt A):164-71.

79. Mollersen L, Rowe AD, Larsen E, Rognes T, Klungland A. Continuous and periodic expansion of CAG repeats in Huntington's disease R6/1 mice. PLoS Genet. 2010;6(12):e1001242.

80. Goula AV, Stys A, Chan JP, Trottier Y, Festenstein R, Merienne K. Transcription elongation and tissuespecific somatic CAG instability. PLoS Genet. 2012;8(11):e1003051. 
Supplemental Table 1. Descriptions of the male and female rhesus macaques used in these studies. Adol, adolescent; BD, binge drinking; BS, bisulfite sequencing analysis; CAG, trinucleotide repeat genotyping analysis; HD, heavy drinking; LD, low drinking; MA, mature adult; TV, KCNN3 transcript variant analysis; VHD, very heavy drinking; WB, $\mathrm{K}_{\mathrm{Ca}} 2.3$ channel western blotting analysis; $\mathrm{YA}$, young adult.

\begin{tabular}{|c|c|c|c|c|c|c|c|c|c|c|}
\hline \multirow{2}{*}{$\begin{array}{l}\text { MATRR } \\
\text { ID }\end{array}$} & \multirow{2}{*}{ Cohort } & \multirow{2}{*}{ Sex } & \multirow{2}{*}{$\begin{array}{c}\text { EtOH Intake } \\
\text { (g/kg/22 h) }\end{array}$} & \multirow{2}{*}{$\begin{array}{l}\text { Drinking } \\
\text { Category }\end{array}$} & \multirow{2}{*}{$\begin{array}{l}\text { Age (in years) at Start } \\
\text { of EtOH Induction }\end{array}$} & \multirow{2}{*}{$\begin{array}{l}\text { Age } \\
\text { Category }\end{array}$} & \multicolumn{4}{|c|}{ Study Inclusion } \\
\hline & & & & & & & CAG & TV & BS & WB \\
\hline 10048 & 4 & $M$ & 1.25 & LD & 9.85 & MA & Yes & & Yes & \\
\hline 10049 & 4 & $M$ & 2.62 & HD & 9.81 & MA & Yes & Yes & Yes & \\
\hline 10051 & 4 & $M$ & 2.65 & $B D$ & 9.22 & MA & Yes & & & \\
\hline 10052 & 4 & M & 0.47 & LD & 9.18 & MA & Yes & Yes & Yes & \\
\hline 10054 & 4 & $M$ & 2.51 & $\mathrm{BD}$ & 8.03 & MA & Yes & & & \\
\hline 10055 & 4 & $M$ & 1.03 & LD & 8.43 & MA & Yes & Yes & Yes & \\
\hline 10056 & 4 & $M$ & 1.56 & LD & 8.01 & MA & Yes & Yes & Yes & \\
\hline 10057 & 4 & $M$ & 2.29 & $B D$ & 7.05 & MA & Yes & & & \\
\hline 10058 & 4 & $M$ & 1.99 & LD & 7.18 & MA & Yes & Yes & & \\
\hline 10059 & 4 & $M$ & 2.43 & $\mathrm{BD}$ & 7.18 & MA & Yes & & & \\
\hline 10061 & 5 & $M$ & 3.78 & VHD & 5.85 & YA & Yes & Yes & Yes & \\
\hline 10062 & 5 & $M$ & 4.09 & VHD & 5.94 & YA & & & Yes & \\
\hline 10063 & 5 & $M$ & 3.09 & VHD & 5.69 & YA & & & Yes & \\
\hline 10064 & 5 & $M$ & 2.74 & $\mathrm{HD}$ & 5.65 & YA & Yes & & Yes & \\
\hline 10065 & 5 & $M$ & 3.09 & HD & 5.94 & YA & Yes & Yes & Yes & \\
\hline 10066 & 5 & $M$ & 3.27 & VHD & 5.77 & YA & Yes & Yes & Yes & \\
\hline 10067 & 5 & $M$ & 3.08 & $H D$ & 5.81 & YA & Yes & & Yes & \\
\hline 10167 & 5 & $M$ & - & CTRL & - & - & & & Yes & \\
\hline 10169 & 5 & $M$ & - & CTRL & - & - & & & Yes & \\
\hline 10170 & 5 & $M$ & - & CTRL & - & - & & Yes & Yes & \\
\hline 10171 & 5 & $M$ & - & CTRL & - & - & & Yes & Yes & \\
\hline 10208 & 10 & $M$ & 2.29 & $\mathrm{BD}$ & 5.88 & YA & Yes & & & \\
\hline 10209 & 10 & M & 2.39 & BD & 5.84 & YA & Yes & & & \\
\hline 10210 & 10 & $M$ & 1.55 & LD & 6.16 & YA & Yes & & & \\
\hline 10211 & 10 & $M$ & 2.11 & $\mathrm{BD}$ & 5.02 & YA & Yes & & & \\
\hline 10212 & 10 & $M$ & 2.32 & HD & 5.04 & YA & Yes & & & \\
\hline 10213 & 10 & M & 1.29 & LD & 4.74 & Adol & Yes & & & \\
\hline 10214 & 10 & $M$ & 4.22 & VHD & 5.04 & YA & Yes & & & \\
\hline 10215 & 10 & $M$ & 3.19 & VHD & 5.08 & YA & Yes & & & \\
\hline 10068 & $6 a$ & $\mathrm{~F}$ & $\mathrm{n} / \mathrm{a}$ & CTRL & - & - & & & Yes & Yes \\
\hline 10069 & $6 a$ & $\mathrm{~F}$ & 5.15 & VHD & 4.14 & Adol & Yes & Yes & & \\
\hline 10070 & $6 a$ & $\mathrm{~F}$ & 3.92 & VHD & 4.12 & Adol & Yes & Yes & Yes & \\
\hline 10071 & $6 a$ & $\mathrm{~F}$ & - & CTRL & - & - & & Yes & Yes & Yes \\
\hline 10076 & $6 a$ & $\mathrm{~F}$ & - & CTRL & - & - & & Yes & Yes & Yes \\
\hline 10078 & $6 a$ & $\mathrm{~F}$ & 5.04 & VHD & 3.84 & Adol & Yes & Yes & Yes & Yes \\
\hline 10079 & $6 a$ & $\mathrm{~F}$ & 4.02 & VHD & 4.16 & Adol & Yes & Yes & Yes & Yes \\
\hline 10080 & $6 a$ & $F$ & 3.27 & VHD & 4.16 & Adol & Yes & Yes & Yes & Yes \\
\hline 10081 & $6 a$ & $\mathrm{~F}$ & 4 & VHD & 4.16 & Adol & Yes & Yes & & Yes \\
\hline 10072 & $6 b$ & $\mathrm{~F}$ & 1.05 & LD & 5.83 & YA & Yes & & & Yes \\
\hline 10073 & $6 b$ & $\mathrm{~F}$ & 3.94 & VHD & 5.63 & YA & Yes & Yes & Yes & \\
\hline 10074 & $6 b$ & $\mathrm{~F}$ & 1.71 & LD & 5.58 & YA & Yes & & & \\
\hline 10075 & $6 b$ & $F$ & 2.78 & $\mathrm{HD}$ & 5.83 & YA & Yes & & & \\
\hline 10077 & $6 b$ & $\mathrm{~F}$ & 1.34 & LD & 6.04 & YA & Yes & & & \\
\hline 10186 & $6 b$ & $\mathrm{~F}$ & - & CTRL & - & - & & Yes & Yes & Yes \\
\hline 10187 & $6 b$ & $\mathrm{~F}$ & - & CTRL & - & - & & Yes & & Yes \\
\hline 10188 & $6 b$ & $\mathrm{~F}$ & - & CTRL & - & - & & Yes & & \\
\hline 10087 & $7 a$ & $M$ & 2.36 & BD & 4.36 & Adol & Yes & & & \\
\hline
\end{tabular}


bioRxiv preprint doi: https://doi.org/10.1101/713826; this version posted July 24,2019 . The copyright holder for this preprint (which was not certified by peer review) is the author/funder. All rights reserved. No reuse allowed without permission.

\begin{tabular}{|c|c|c|c|c|c|c|c|c|c|}
\hline 10088 & $7 a$ & $\mathrm{M}$ & 2.89 & HD & 4.49 & Adol & Yes & Yes & \\
\hline 10089 & $7 a$ & $\mathrm{M}$ & 2 & LD & 4.65 & Adol & Yes & Yes & Yes \\
\hline 10090 & $7 a$ & $\mathrm{M}$ & 1.85 & LD & 4.25 & Adol & Yes & Yes & Yes \\
\hline 10091 & $7 a$ & $\mathrm{M}$ & 3.15 & VHD & 4.34 & Adol & Yes & Yes & \\
\hline 10092 & $7 a$ & $\mathrm{M}$ & 1.9 & LD & 4.29 & Adol & Yes & Yes & Yes \\
\hline 10093 & $7 a$ & $\mathrm{M}$ & - & CTRL & - & - & & Yes & Yes \\
\hline 10094 & $7 a$ & $\mathrm{M}$ & - & CTRL & - & - & & Yes & Yes \\
\hline 10096 & $7 a$ & $\mathrm{M}$ & - & CTRL & - & - & & Yes & Yes \\
\hline 10097 & $7 a$ & $\mathrm{M}$ & 3.03 & HD & 4.33 & Adol & Yes & Yes & Yes \\
\hline 10098 & $7 a$ & $\mathrm{M}$ & 3.32 & VHD & 3.99 & Adol & Yes & Yes & \\
\hline 10082 & $7 b$ & $\mathrm{M}$ & 2.42 & HD & 6.30 & YA & Yes & Yes & Yes \\
\hline 10083 & $7 b$ & $\mathrm{M}$ & 1.44 & LD & 5.80 & YA & Yes & Yes & Yes \\
\hline 10084 & $7 b$ & $\mathrm{M}$ & 1.85 & LD & 5.66 & YA & Yes & Yes & Yes \\
\hline 10085 & $7 b$ & $\mathrm{M}$ & 2.07 & LD & 5.87 & YA & Yes & Yes & \\
\hline 10086 & $7 b$ & $\mathrm{M}$ & 2.28 & $B D$ & 5.64 & YA & Yes & & \\
\hline 10182 & $7 b$ & $\mathrm{M}$ & - & CTRL & - & - & & Yes & Yes \\
\hline 10183 & $7 b$ & $\mathrm{M}$ & - & CTRL & - & - & & Yes & Yes \\
\hline 10184 & $7 b$ & $\mathrm{M}$ & - & CTRL & - & - & & Yes & \\
\hline 10185 & $7 b$ & $\mathrm{M}$ & - & CTRL & - & - & & Yes & \\
\hline
\end{tabular}


Supplemental Table 2. Primers used for bisulfite amplicon sequencing.

\begin{tabular}{|c|c|c|c|c|c|}
\hline Species & $\begin{array}{l}\text { Genomic } \\
\text { sequence }\end{array}$ & Primer & Position* & Sequence & $\begin{array}{c}\text { Amplicon } \\
\text { length }\end{array}$ \\
\hline \multirow{3}{*}{$\begin{array}{l}\text { Macaca } \\
\text { mulatta }\end{array}$} & \multirow{3}{*}{ NC_027893.1 } & $\begin{array}{l}\text { Pair 1-Forward } \\
\text { Pair 1-Reverse }\end{array}$ & $\begin{array}{l}129559145 \\
129559405\end{array}$ & $\begin{array}{l}\text { TTTTTGAGTATAAATTTTAAGAGAGTT } \\
\text { AAAACAACCATACCCACCAAAC }\end{array}$ & $261 \mathrm{bp}$ \\
\hline & & $\begin{array}{l}\text { Pair 2-Forward } \\
\text { Pair 2-Reverse }\end{array}$ & $\begin{array}{l}129559386 \\
129559660\end{array}$ & $\begin{array}{l}\text { TTGGTGGGTATGGTTGTTTTT } \\
\text { TCTCCAAATTCCACAACTACAAATA }\end{array}$ & 275 bp \\
\hline & & $\begin{array}{l}\text { Pair 3-Forward } \\
\text { Pair 3-Reverse }\end{array}$ & $\begin{array}{l}129559511 \\
129559790\end{array}$ & $\begin{array}{l}\text { GGTTGAGGGGTTTTATGATTTTAT } \\
\text { САСССTAACСTACTACАСTССTСTC }\end{array}$ & $280 \mathrm{bp}$ \\
\hline $\begin{array}{c}\text { Mus } \\
\text { musculus }\end{array}$ & NC_000069.6 & $\begin{array}{l}\text { Pair 1-Forward } \\
\text { Pair 1-Reverse } \\
\text { Pair 2-Forward } \\
\text { Pair 2-Reverse }\end{array}$ & $\begin{array}{r}726 \\
1000 \\
981 \\
1241\end{array}$ & $\begin{array}{l}\text { TTGGTGGGTATGGTTATTTT } \\
\text { CTCCAAATTCCACAACCACAAAT } \\
\text { TTTTTGAGTATAAATTTTAAGATAGTT } \\
\text { AAAATAACCATACCCACCAAAC }\end{array}$ & 275 bp \\
\hline
\end{tabular}

*Position from the transcription start site (TSS). 
Supplemental Table 3. Nucleotide sequences of primers used for quantitative PCR.

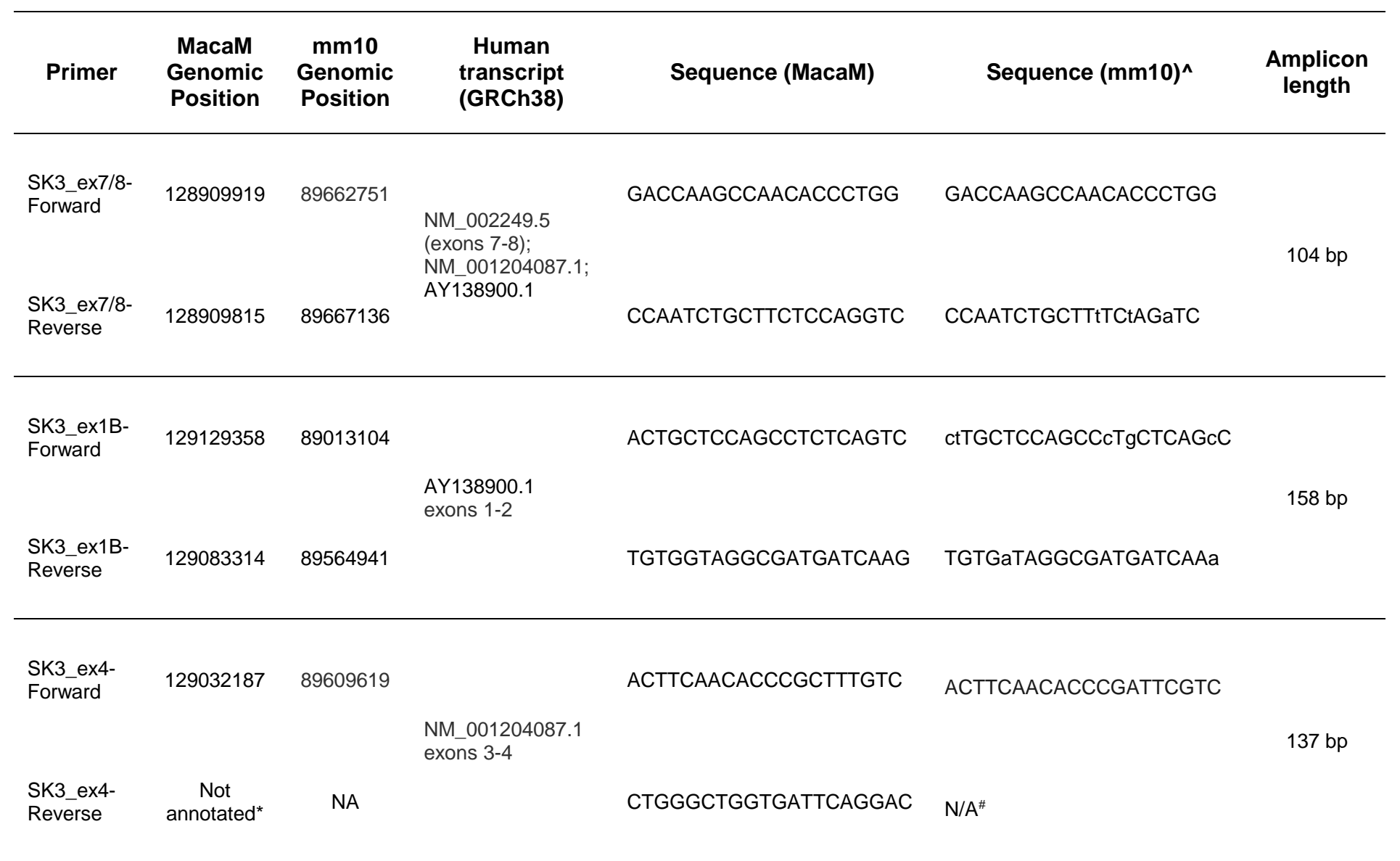

*Although the homologous exon 4 of the human TV NM_001204087.1 is not annotated in MacaM, it is in the most updated version of the macaque genome (Mmul8).

Nower case letters represent non-conserved nucleotides between macaques and mice.

\#sequence not annotated in the mouse genome, we used the macaque primer instead. 
bioRxiv preprint doi: https://doi.org/10.1101/713826; this version posted July 24,2019 . The copyright holder for this preprint (which was not certified by peer review) is the author/funder. All rights reserved. No reuse allowed without permission.

Supplemental Table 4. KCNN3 transcript variants, protein isoforms, and channel function.

\begin{tabular}{|c|c|c|c|c|}
\hline Transcript Variant & $\begin{array}{l}\text { Unique } \\
\text { exons }\end{array}$ & Protein isoform & Changes in protein structure & $\begin{array}{l}\text { Altered Channel } \\
\text { Function }\end{array}$ \\
\hline $\begin{array}{l}\text { SK3_1A } \\
\text { (NM_002249.5) }\end{array}$ & $1 \mathrm{~A}$ & $\begin{array}{l}\text { 1: Full-Length } \\
\text { (NP_002240.3) }\end{array}$ & None & None \\
\hline $\begin{array}{l}\text { SK3_1B } \\
(\text { NM_170782.2) }\end{array}$ & 1B & 3 (NP_740752.1) & $\begin{array}{l}\text { Lacks S1 transmembrane domain; Missing aa1- } \\
318\end{array}$ & Dominant-negative \\
\hline $\begin{array}{l}\text { SK3_1C } \\
\text { (AY138900.1) }\end{array}$ & $1 \mathrm{C}$ & 2 (AAN46636.1) & $\begin{array}{l}\text { Lacks S1 transmembrane domain; missing aa1- } \\
\text { 310; 311-315: WGLYS } \rightarrow \text { MERPI }\end{array}$ & $\begin{array}{l}\text { Dominant-negative; Very } \\
\text { low CNS expression }\end{array}$ \\
\hline $\begin{array}{l}\text { SK3_ex4 } \\
(\text { NM_001204087.1) }\end{array}$ & 4 & $\begin{array}{l}\text { SK3_ex4 } \\
\text { (NP_001191016) }\end{array}$ & 15 amino-acid insert in the pore-forming loop & Apamin-insensitive \\
\hline
\end{tabular}




\section{Figure Legends}

Fig. 1. Ethanol consumption for the monkeys and mice using in the current study. a Average daily ethanol $(4 \% \mathrm{v} / \mathrm{v})$ intake in male and female rhesus macaques and their drinking category during 12 months of open access. Also shown is their age at the time of first ethanol exposure and the $\%$ days where they consumed $>3$ g/kg/22 h. Adol, adolescent; BD, binge drinking; HD, heavy drinking; LD, low drinking; MA, mature adult; VHD, very heavy drinking; YA, young adult. b Daily ethanol $(15 \% \mathrm{v} / \mathrm{v})$ intake values in male C57BL/6J mice prior to and after each of four cycles of chronic intermittent ethanol (CIE) exposure in vapor inhalation chambers $(n=15$ mice/group). c Average weekly ethanol intake in mice during the week prior to and after each cycle of $\mathrm{CIE}$ exposure (Tukey post hoc, ${ }^{\star \star \star} p=0.0074$ vs test 1 air group; ${ }^{\star} p=0.0468$ vs test 2 air group; ${ }^{\star \star} p=0.0034$ vs test 3 air group; ${ }^{* \star *} p=<0.0001$ tests $1-4$ vs baseline CIE group).

Fig. 2. KCNN3 methylation levels within MR-ex1-200 of ethanol drinking monkeys and dependent mice. The average methylation rates of individual CpGs included in the methylation region under study are shown. a Exon organization of the KCNN3 locus showing the location of exons and the dual CAG trinucleotide repeat arrays and methylated region in exon 1 (MR-ex1). b In rhesus macaque, the following CpGs showed elevated rates of methylation in heavy/very heavy drinking macaques vs controls: $\mathrm{CpG}_{129130376:} \mathrm{F}(2,11.846)=7.9,{ }^{\star} p=$ 0.04; $\mathrm{CpG}_{129130680:} \mathrm{F}(2,15.955)=3.661,{ }^{\star} p=0.036 ; \mathrm{CpG}_{129130739}: \mathrm{F}(2,15.468)=3.817,{ }^{\star} p=0.04 ; \mathrm{CpG}_{129130770}$ : $\mathrm{F}(2,13.57)=5.047,{ }^{\star} p=0.041 ; \mathrm{CpG}_{129130792}: \mathrm{F}(2,13.945)=7.047,{ }^{\star} p=0.01 ; \mathrm{CpG}_{129130816:} \mathrm{F}(2,15.63)=5.836$, ${ }^{\star} p=0.015 ; \mathrm{CpG}_{129130832}: \mathrm{F}(2,15.473)=3.95,{ }^{\star} p=0.033 ; \mathrm{CpG}_{129130931}: \mathrm{F}(2,14.393)=4.016,{ }^{\star} p=0.038$; $\mathrm{CpG}_{129130964:} \mathrm{F}(2,15.708)=3.985,{ }^{*} p=0.031$. $\mathrm{c}$ In female macaques, elevated rates of methylation were observed at the following CpGs in very heavy drinking macaques vs controls: $\mathrm{CpG}_{129130612}: \mathrm{F}(1,7)=6.122,{ }^{*} p=$ 0.048; $\mathrm{CpG}_{129130632:} \mathrm{F}(1,7)=7.64,{ }^{\star} p=0.033 ; \mathrm{CpG}_{129130685}: \mathrm{F}(1,7)=13.370,{ }^{\star} p=0.011 ; \mathrm{CpG}_{129130699:} \mathrm{F}(1,7)=$ 7.799, ${ }^{\star} p=0.031$. $\mathbf{d}$ In mouse accumbens, the following CpGs showed elevated rates of methylation between

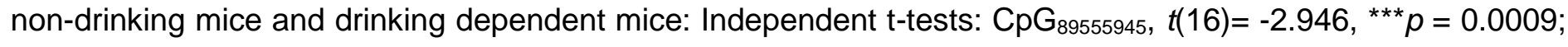
$\mathrm{CpG}_{89555974}, t(17)=-2.860,{ }^{\star} p=0.011 ; \mathrm{Cp}_{\mathrm{G} 89556220}, t(17)=-2.206,{ }^{\star} p=0.042$. 
Fig. 3. Summary of nucleus accumbens $K C N N 3$ transcript expression in ethanol drinking rhesus macaques and C57BL/6J mice. a-c The relative expression of brain KCNN3 transcripts (SK3_ex7/8, 1 SK3_ex1B, and SK3_ex4) among the three drinking macaque groups (SK3_ex1B: ${ }^{*} p=0.0381$ vS CTRL; SK3_ex4: ${ }^{\star *} p=0.0084$ vs CTRL, ${ }^{\star \star \star} p=0.0009$ vs CTRL). d-f The relative expression of the KCNN3 transcripts in drinking monkeys collapsed by age at onset of ethanol drinking (SK3_ex4: ${ }^{\star *} p<0.0015$ vs CTRL). g-i The relative expression of the $K C N N 3$ transcript variants in the accumbens of male C57BL/6J mice that were treated with CIE exposure (SK3_ex1B: * $p<0.026$ CIE exposed drinkers vs all remaining groups; SK3_ex4: **p $<0.015$ drinkers vs non-drinkers).

Fig. 4. Adaptations in nucleus accumbens $K C N N 3$ transcript and protein expression in ethanol drinking female rhesus macaques. a-c The relative expression of KCNN3 transcripts (SK3_ex7/8, 1 SK3_ex1B, and SK3_ex4) among control and very heavy drinking macaque groups (SK3_ex1B: * $p=0.037$ vs CTRL; SK3_ex4: ${ }^{*} p=0.024$ vs CTRL). $\mathbf{d}$ Characterization of anti-K $\mathrm{K}_{\mathrm{ca}} 2.3$ channel western blot in macaque accumbens tissue (protein loading range, $1.25-40 \mu \mathrm{g}$ ). e Positive correlation between the amount of protein loaded and anti$\mathrm{K}_{\mathrm{ca}} 2.3$ channel optical density values. $\mathbf{f , g}$ The full $\mathrm{K}_{\mathrm{ca}} 2.3$ channel blot and quantitation of normalized $\mathrm{K}_{\mathrm{ca}} 2.3$ channel protein expression in controls and drinkers ( ${ }^{\star} p=0.0324$ vs CTRL).

Fig. 5. KCNN3-CAGn allele frequency distribution among male and female rhesus macaques. a The frequency distribution of (CAG)n alleles is shown for low drinkers (LD), binge drinkers (BD), heavy drinkers (HD), and very heavy drinkers (VHD). b Correlation between CAG repeat sum and average ethanol intake. c-e Correlations between CAG repeat sum and KCNN3 transcript expression in long-term drinking rhesus macaques. 
Figure 1
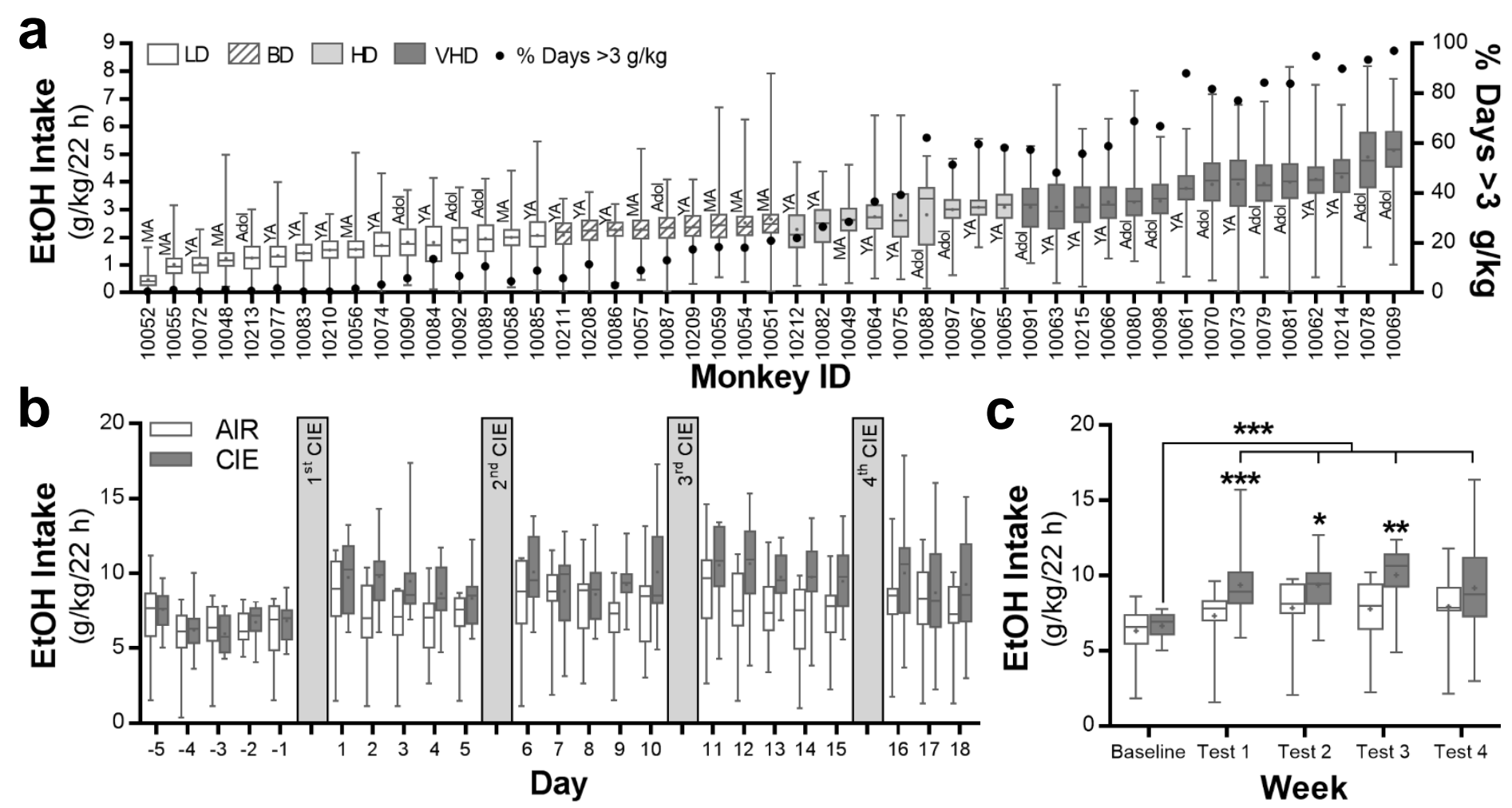
bioRxiv preprint doi: https://doi.org/10.1101/713826; this version posted July 24, 2019. The copyright holder for this preprint (which was not certified by peer review) is the author/funder. All rights reserved. No reuse allowed without permission.

Figure 2

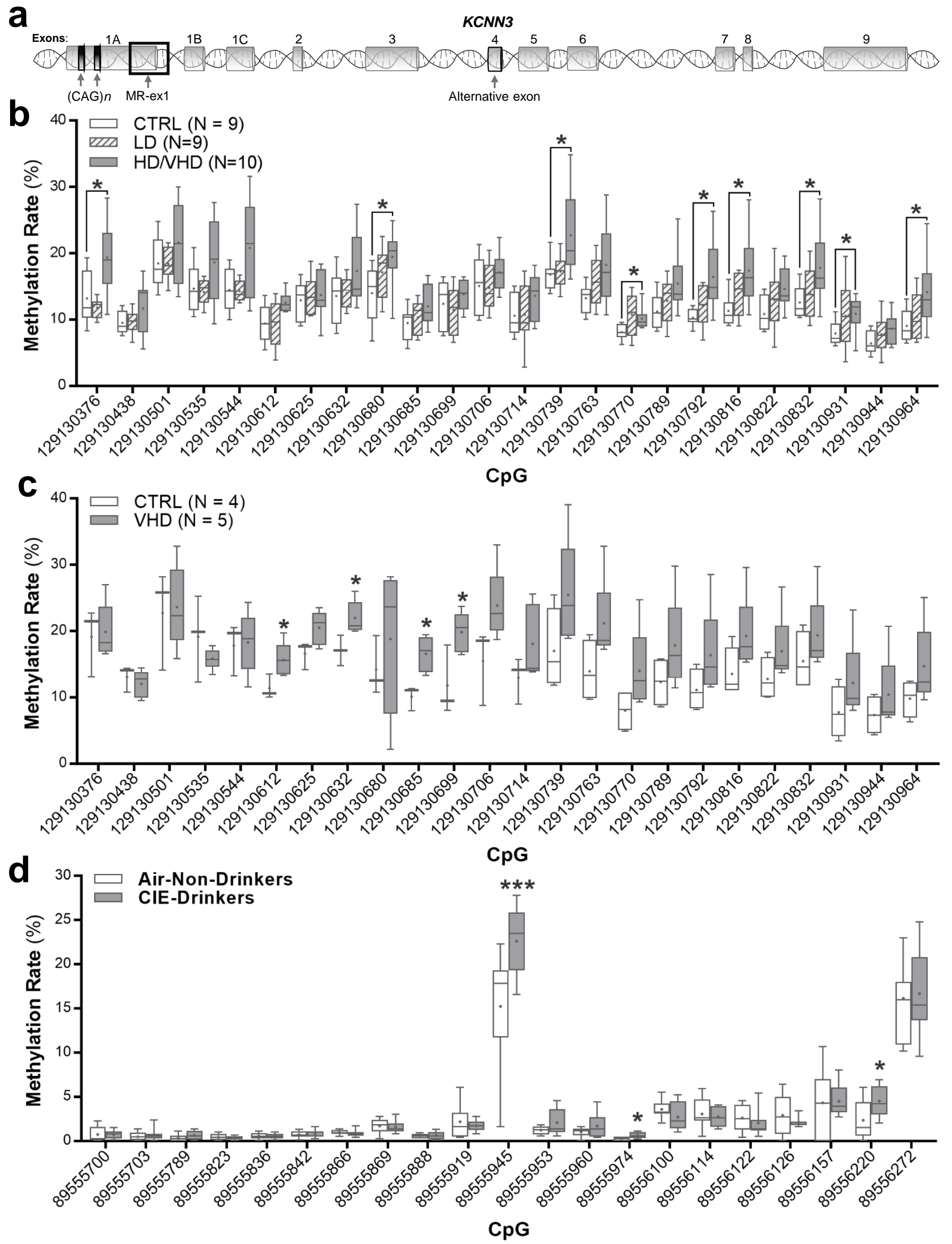


Figure 3
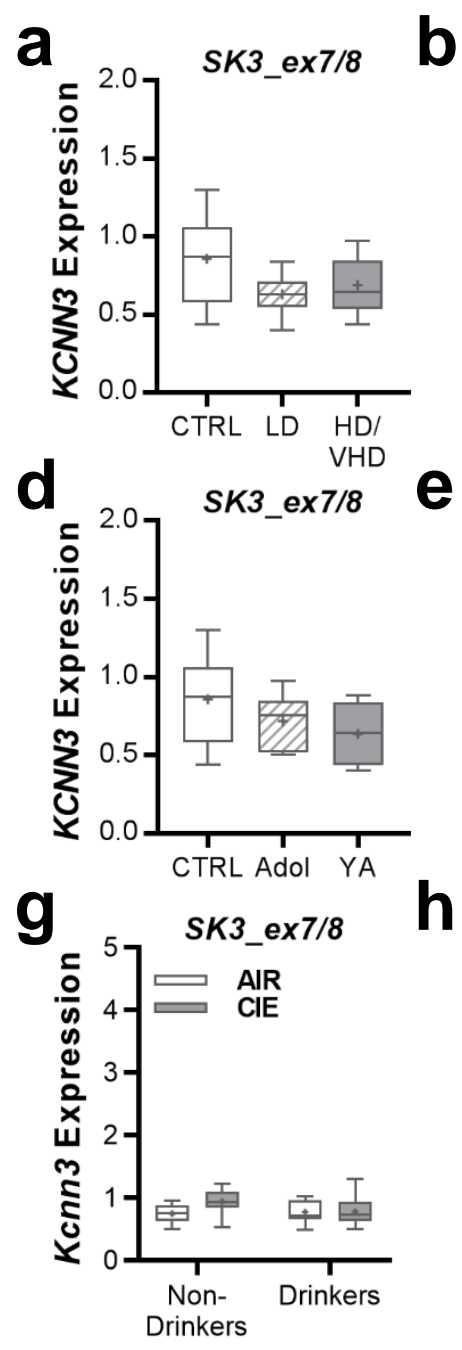

h
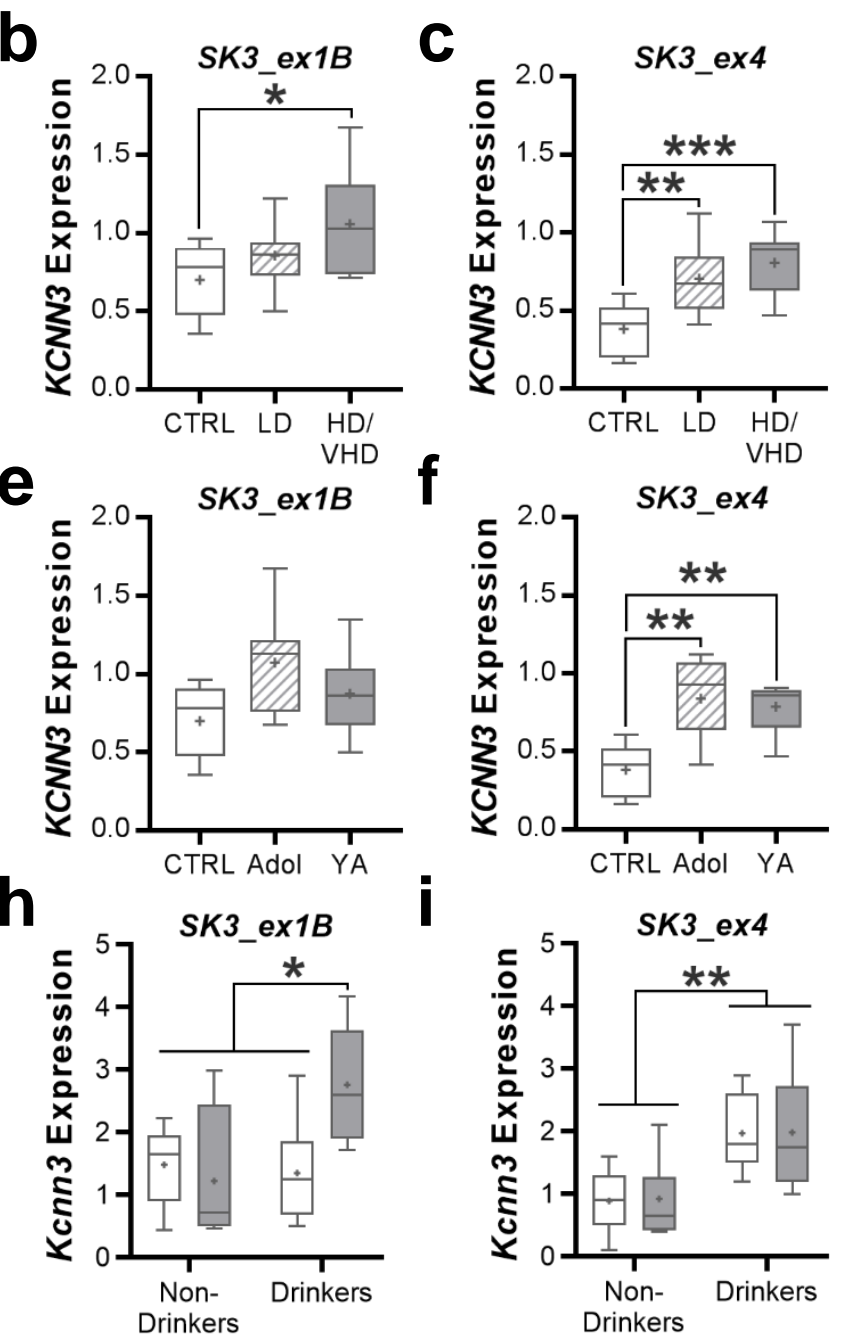
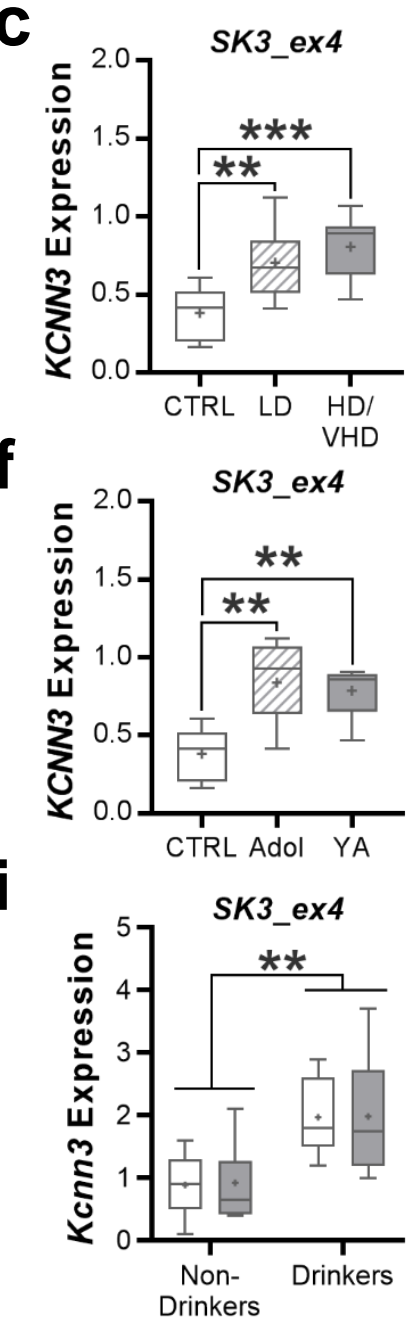
Figure 4

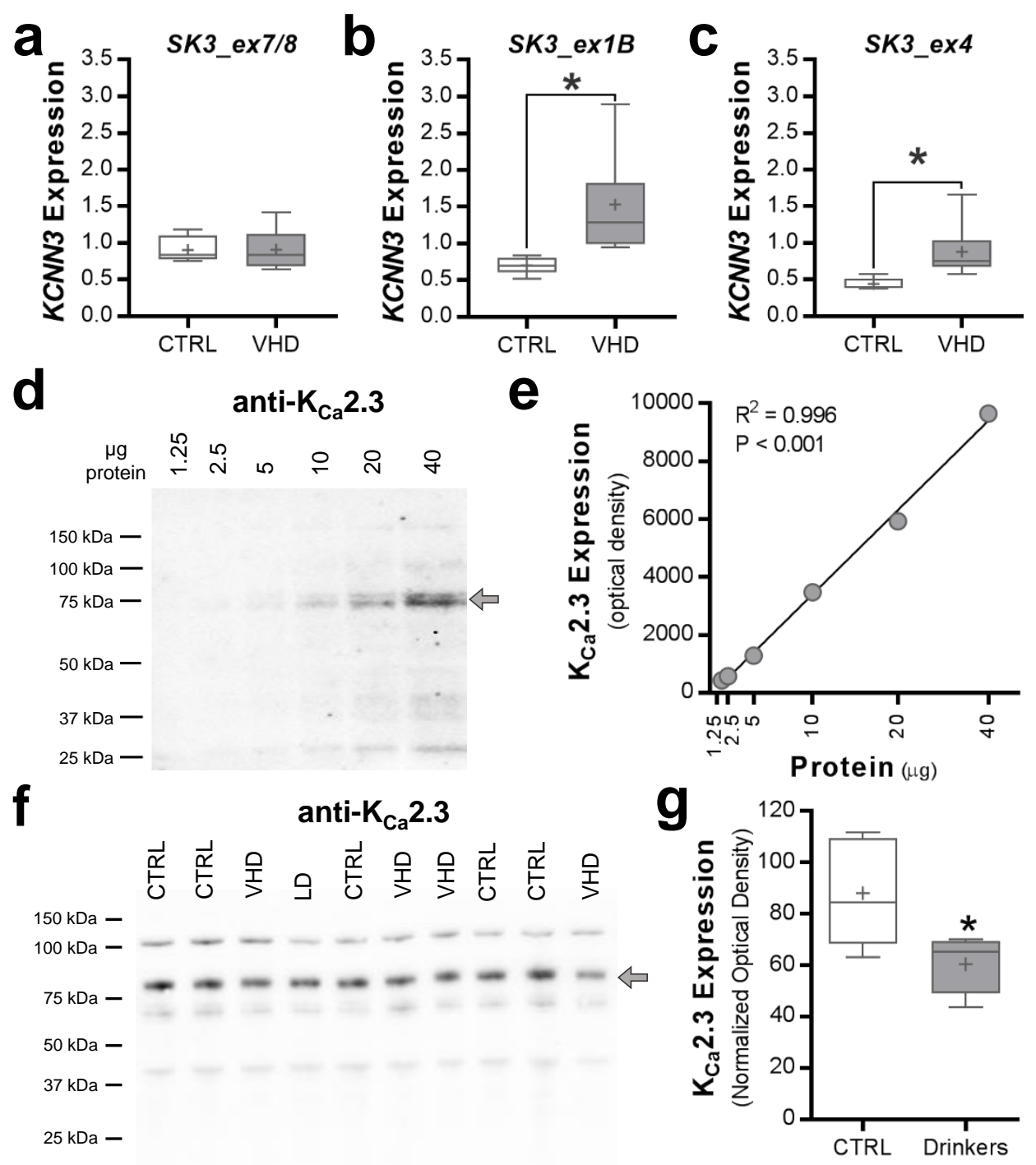


Figure 5
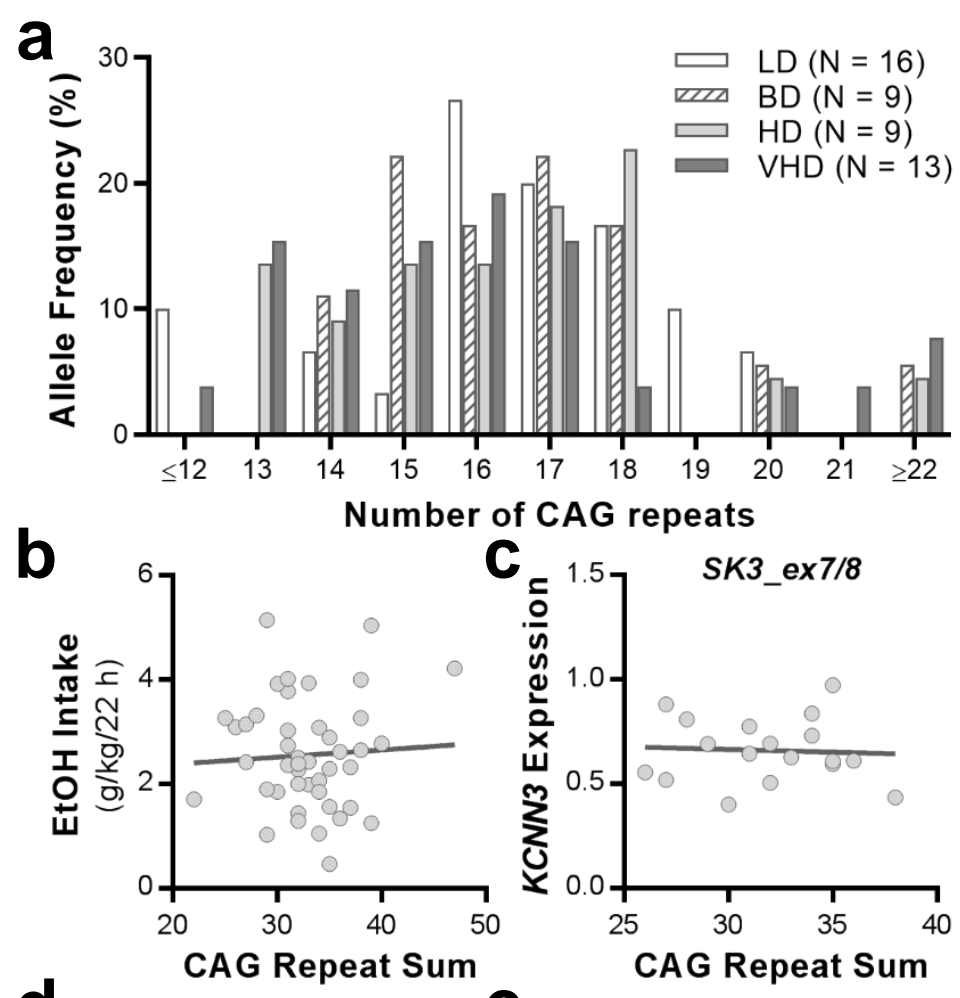

C ${ }^{1.5}$ SK3_ex7/8
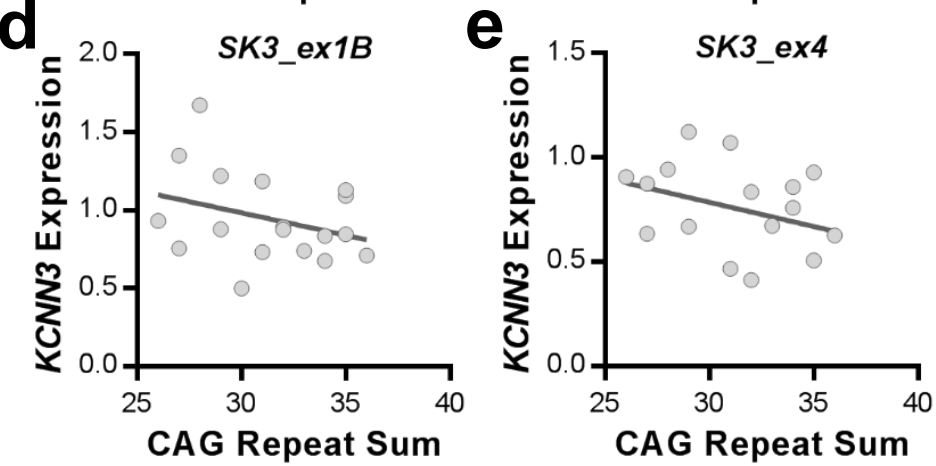
a

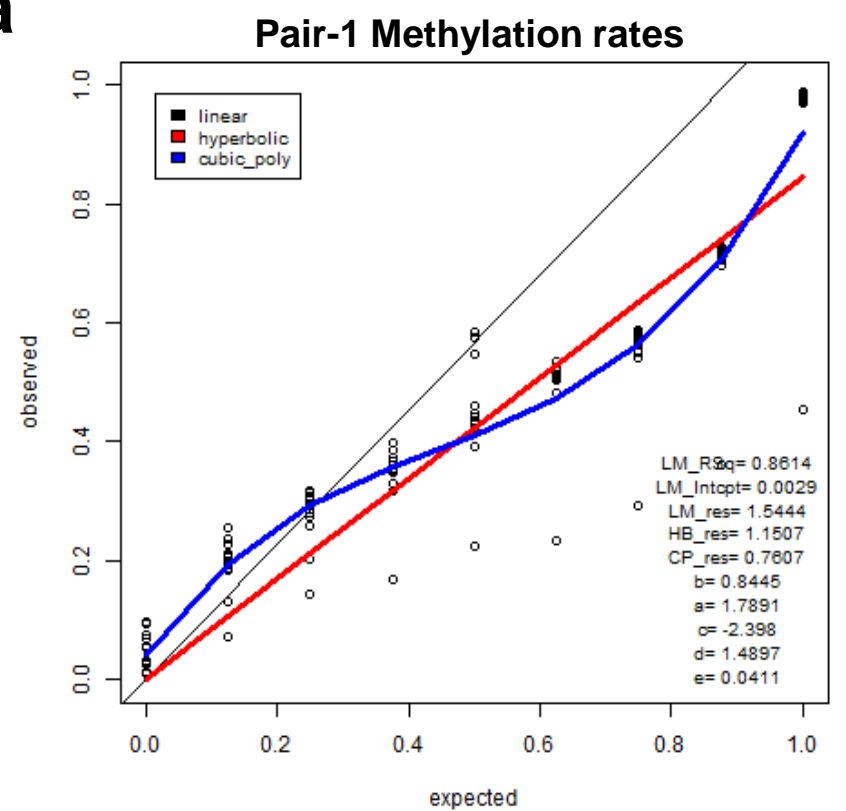

C

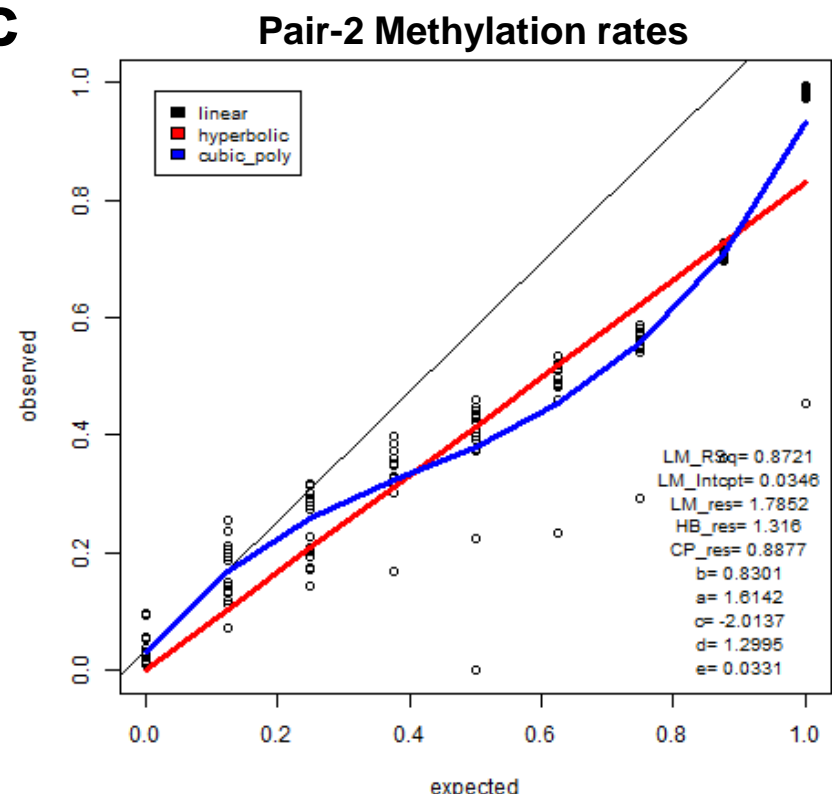

e

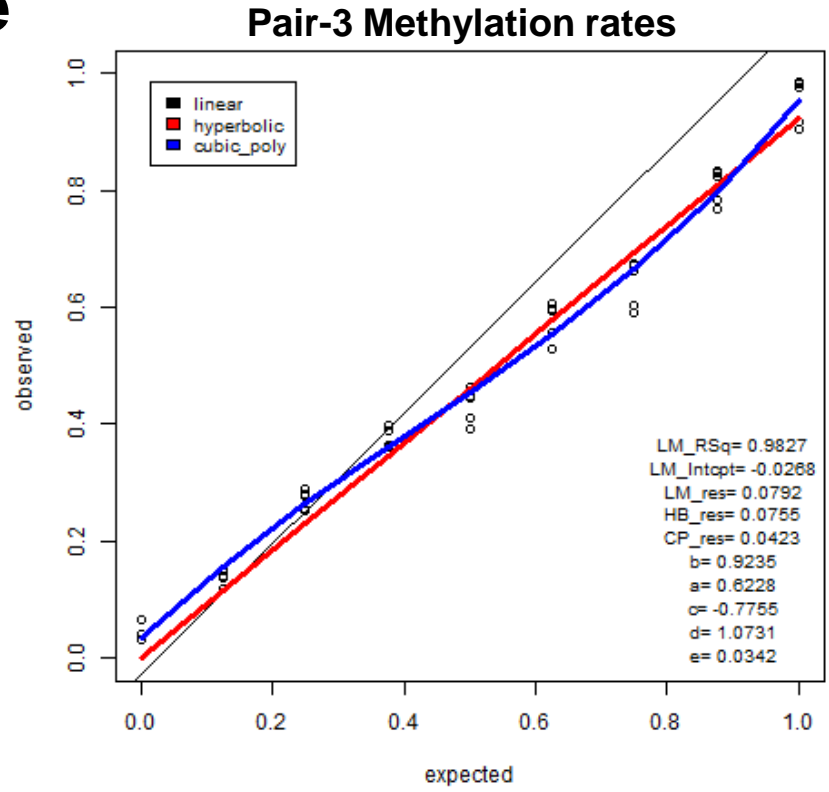

b

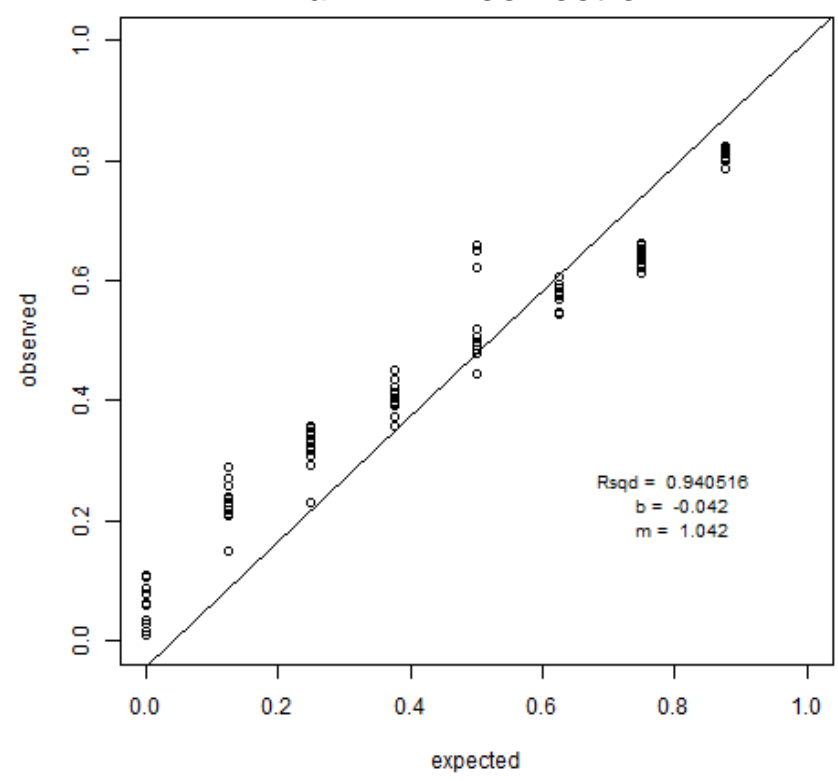

d

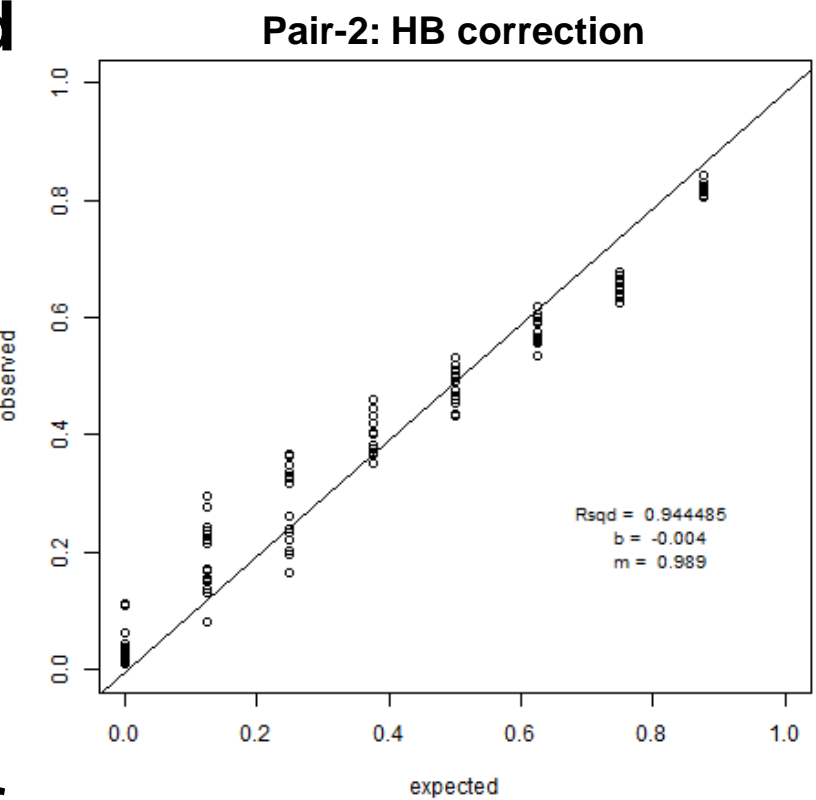

f

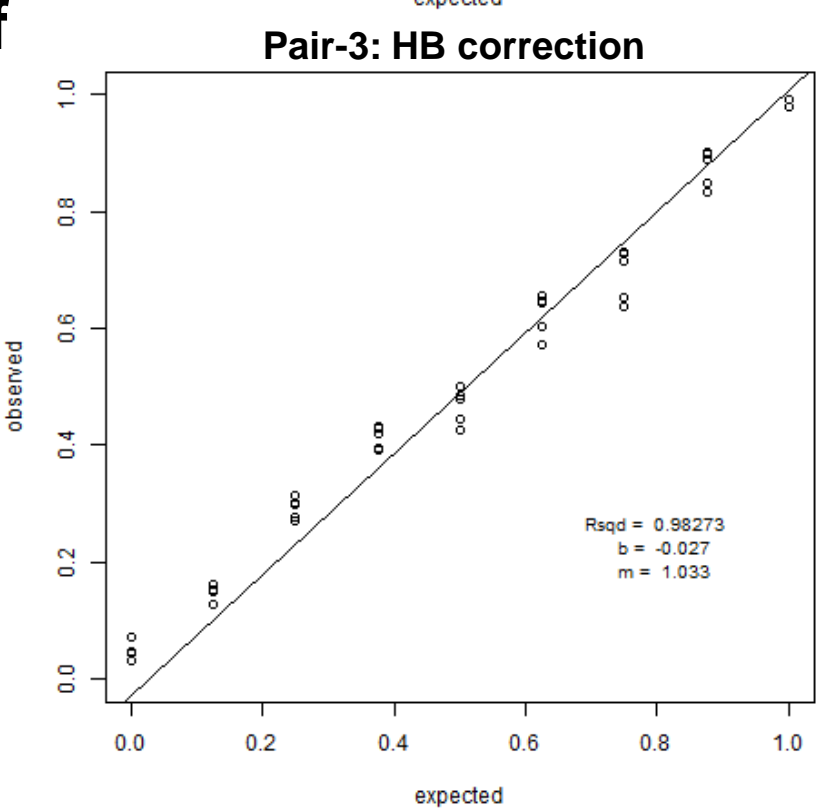

Supplemental Fig. 1. Titration curves to correct for PCR bias during amplification of the methylation region under study. Three different amplicons were used to amplify the complete region 1 (a), 2 (c) and 3 (e). PCR-bias was corrected using the hyperbolic function (HB, $\mathbf{b}, \mathbf{d}$ and $\mathbf{f})$. 
bioRxiv preprint doi: https://doi.org/10.1101/713826; this version posted July 24, 2019. The copyright holder for this preprint (which was not certified by peer review) is the author/funder. All rights reserved. No reuse allowed without permission.

\section{Supplemental Figure 2}

Hs 154,868,982 ACCTACATATTCCTTTTGTTCAAGGTATAAAGAGAAACCACAGCCCCTACCTTTGAGTAC 154,869,041 Rm 129,130,300 ACCTACATATTCCTTTTGTTCAAGGTATAAAGAGAAACCACAGCCCCTACCTTTGAGTAC 129,130,359 Mm 89,521,452 --CTACATACTCCTTTTGTTGAATGTATAAAGAGAAACCACAG TCCCTACCTTTGAGTAC 89,521,395 Hs $154,869,042$ AAACCCCAAGAGAGCTC̈GGTCTCTATCACCATAACAACAATTCCAAACATCCCAAAAATC 154,869,101 Rm 129,130,360 AAACCCCAAGAGAGCTCGGTCTCTATCACCATAACAACAATTCCAAACATCCCAAAAATC 129,130,419 Mm 89,521,394 AAACCCCAAGACAG TTCGGTCTCTATCACCATAACAACAATTCCAAACATCCCAAAAATC $89,521,335$ *

Hs 154,869,102 AGAGCATAGTCACTCAGTCGCTTTCTCTTTTCAAACAGGGCCCTCCTGTGTCCCAGCTTA 154,869,161 Rm 129,130,420 AGAGCATAGTCACTCAGTCGCTTTCTCTTTTCAAACAGGGCCCTCCTGTGTCCCAGCTTA 129,130,479 Mm 89,521,334 AGAGCATAGTCACTCAGTCGCTTTCTCTTTTCAAACAGGGCCCTCCTGTGTCCCAGCTTA 89,521,275

Hs 154,869,162 TAGCCAATGTTTTGGTTTTTCCGCTTGTTGGCTTTGGGGAAGGTGGTGCTGCTGGCGGTG 154,869,221 Rm 129,130,480 TAGCCAATGTTTTGGTTTTTCCGCTTGTTGGCTTTGGGGAAGGTGGTGCTGCTGGCGGTG 129,130,539 Mm 89,521,274 TAGCCAATGTTTTGGTTTTTCCGCTTGTTGGCTTTGGGGAAGGTGGTGCTGC $\underline{\text { CG }}$ C $\underline{\text { CGTG }}$ 89,521,215

Hs 154,869,222 GTGCCGGCATGCTGGTGGTTGTGGGTGGCATTAGGGTGATGGAGCAGGGTCTGGTGGGCA 154,869,281 Rm 129,130,541 GTGCCGGCATGCTGGTGGTTGTGGGTGGCATTAGGGTGATGGAGCAGGGTCTGGTGGGCA 129,130,599 Mm 89,521,214 GTGCCGGCATGCTGGTGGTTGTGGGTAGCGTTGGGGTGATGGAGCAGAGTCTGGTGGGCA 89,521,155

Hs 154,869,282 TGGTTGTCCTCCC̈GGGAGGAGATGACGATCTCC̈GGGGGGTTGCTAGGGCTGAAAAGCTGG 154,869,341 Rm 129,130,600 TGGTTGTCCTCCCGGGAGGAGATGACGATCTCCGGGGGGTTGCTAGGACTGAAAAGCTGG 129,130,659 Mm 89,521,154 TGGTTATCCTCCCTGGAGGAGATGA TAATCTCTGGGGGGTTGCTGGGACTGAAGAGCTGG 89,521,095

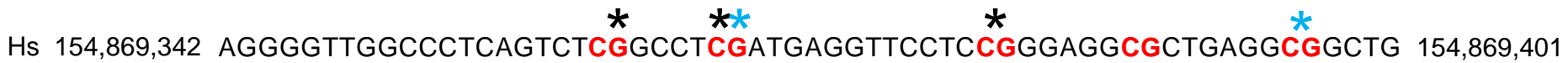
Rm 129,130,660 AGGGGTTGGCCCTCAGTCTCCGCCTCGATGAGGTTCCTCCGGGAGGCGCTGAGGCGGCTG $129,130,719$ Mm 89,521,094 AGGGGTTGGCCCTCAGGCTCAGCCTCGATAAGGTTTCTCCGAGAGGCGCTGAGGCGGCTG 89,521,035

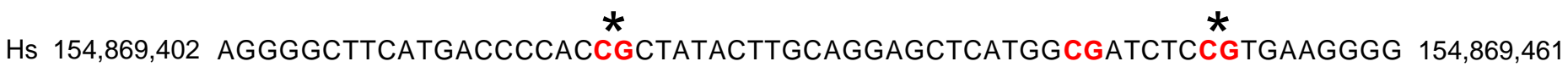
Rm 129,130,720 AGGGGCTTCATGACCCCACCGCTATACTTGCAGGAGCTCATGGCGATCTCCGTGAAGGGG 129,130,779 Mm 89,521,034 AGGGGCTTCATGACCCCACCGCTGTATTTGCAGGAGCTCATAGCTATCTCCGTGAAGGGA 89,520,975

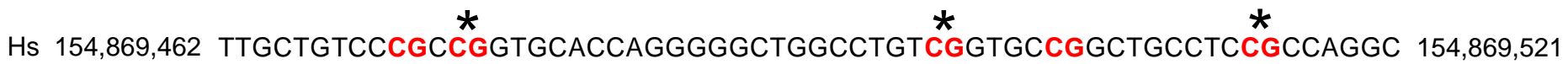
Rm 129,130,780 TTGCTGTCCCGCCGGTGCACCAGGGGGCTGGCCTGCCGGTGCCGGCTGCCTCCGCCAGGC 129,130,839 Mm 89,520,974 TTGCTGTCCCGCCGGTGCACCAGGGGGCTGGCCTGCCGGTGCCGGCTGCCTCCACCGGGC 89,520,915

Hs 154,869,522 CCACTTGTAGCTGTGGAACTTGGAGAGTGGCCAAGCAAGTGGTCATTGAGATTGAGCTGG 154,869,581 Rm 129,130,840 CCACTTGTAGCTGTGGAACTTGGAGAGTGGCCAAGCAAGTGGTCATTGAGATTGAGCTGG 129,130,899 Mm 89,520,914 CCACTTGTGGCTGTGGAACTTGGAGAGTGGCCAAGCAAGTGGTCATTGAGATT TAGCTGG 89,520,855 Hs 154,869,582 CTGCCTTGCCTGGAGGAAGGGTGGAGGATGGCGGTGGAGTTGGACGAAGGGGGGGCCCTG 154,869,641 Rm 129,130,900 CTGCCTTGCCTGGAGGAAGGGTGGAGGATGGCGGTGGAGTTGGACGAAGGGGGGGGCCTG 129,130,959 Mm 89,520,854 CTGCCTTGCCTGGAGGAAGGGTGGAGGATGGCGGTAGAGTTGGCTGAAGTGGGGGCCCTG 89,520,795 Hs 154,869,642 AAAGCGGTGGGAGAGGAGTGCAGCAGGCCAGGGTGGACGGGCTGGCTCTGGAGTTGGGCG 154,869,701 Rm 129,130,960 AAAGCGGTGGGAGAGGAGTGCAGCAGGCCAGGGTGGACGGGCTGGCTCTGGAGTTGGGCG 129,131,019 Mm 89,520,794 AACGCEGTGGGAGAAGAGTGCAACAGACC-AGGATGGAC-AAGCTGGCTCTGGAGTTGGGCA 89,520,735

Supplemental Fig. 2. Sequence homology of MR-ex 1 (exon 1/intron 1) across human, macaque and mouse. The start and stop of the differentially methylated region spanning 646 base pairs is shown by green and red arrows, respectively. Conserved CpGs within MR-ex1 are shown in bold, red font. CpGs unique to a species are underlined. Nucleotides that are not conserved across species are shown in italic. '*' and ' ' are CpGs that are significantly different in HD/VHD monkeys and CIE-exposed drinking mice, respectively. 
bioRxiv preprint doi: https://doi.org/10.1101/713826; this version posted July 24, 2019. The copyright holder for this preprint (which was not certified by peer review) is the author/funder. All rights reserved. No reuse allowed without permission.

\section{Supplemental Figure 3}

\section{KCNN3 MR-ex1}

Hippocampus middle

Substantia nigra

Anterior caudate

Cingulate gyrus

Inferior temporal lobe

Anterior gyrus

Dorsolateral prefrontal

cortex

Supplemental Fig. 3. Overlap of the macaque homologous methylation region within MR-ex1 on the human Roadmap 25 chromatin states. The MR-ex1 region on the human genome (hg19) is located at chr1: $154,841,507-154,842,152$. According to the Roadmap Epigenomic project, the orange color in the 25 chromatin states represents "promoter upstream transcription start site". Note that the nucleus accumbens in not included in the Epigenomics Roadmap database. 


\section{Supplemental Figure 4}
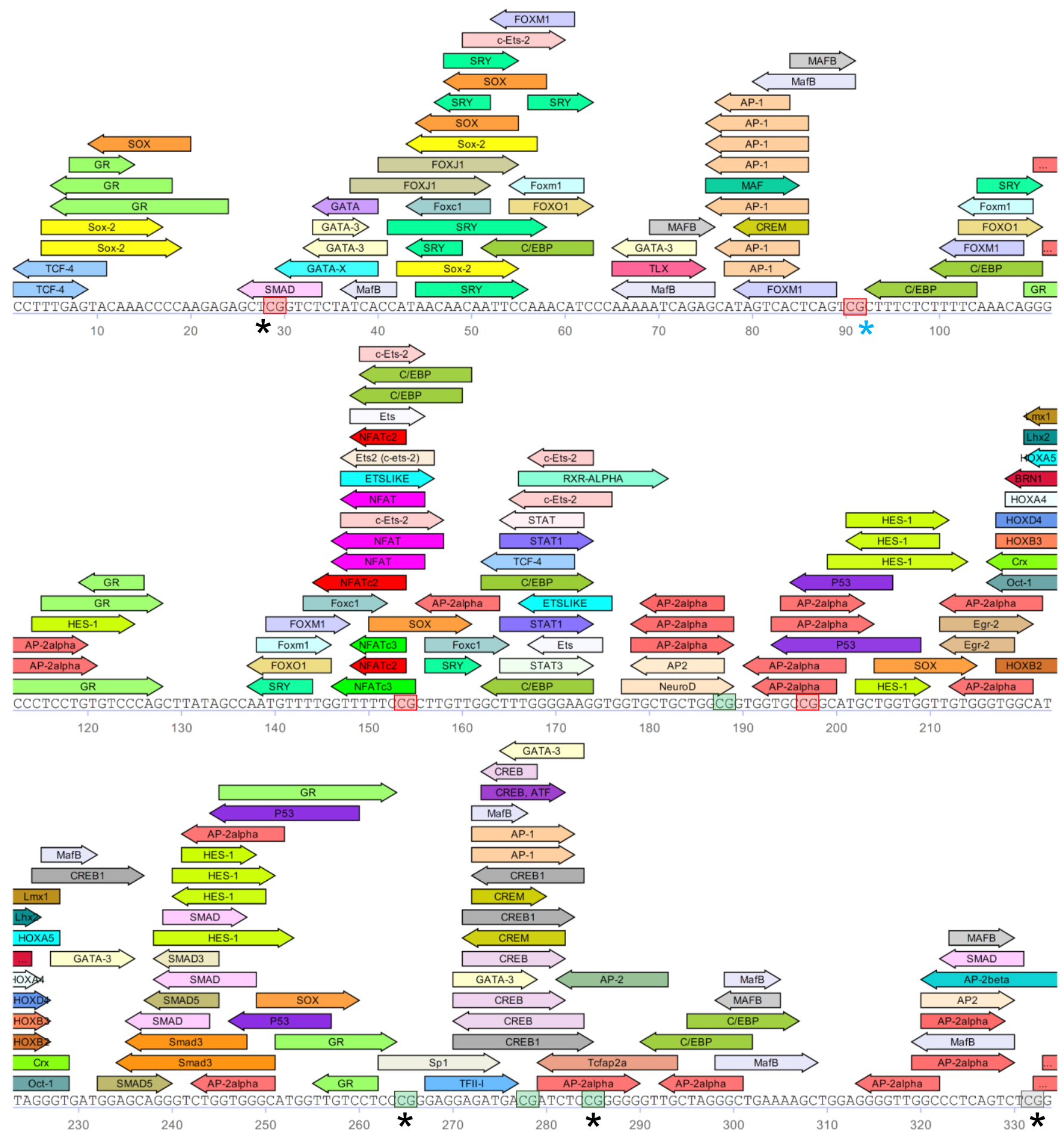

Supplemental Fig. 4. Predicted transcription factors that bind to the human MR-ex1 (TRANSFAC). CpGs enclosed in a red box are conserved in human, monkey and mouse; those CpGs unique to human are enclosed in a grey box, and those conserved in human and monkey are enclosed in a green box. '*' and '*' are CpGs that are significantly different in HD monkeys and CIE-exposed drinking mice, respectively. TRANSFAC conditions were as follows: nerve_system_specific matrices, matrix similarity cut-off: 0.9 and core similarity cut-off: 0.95. 
bioRxiv preprint doi: https://doi.org/10.1101/713826; this version posted July 24,2019 . The copyright holder for this preprint (which was not certified by peer review) is the author/funder. All rights reserved. No reuse allowed without permission.

\section{Supplemental Figure 4, cont.}

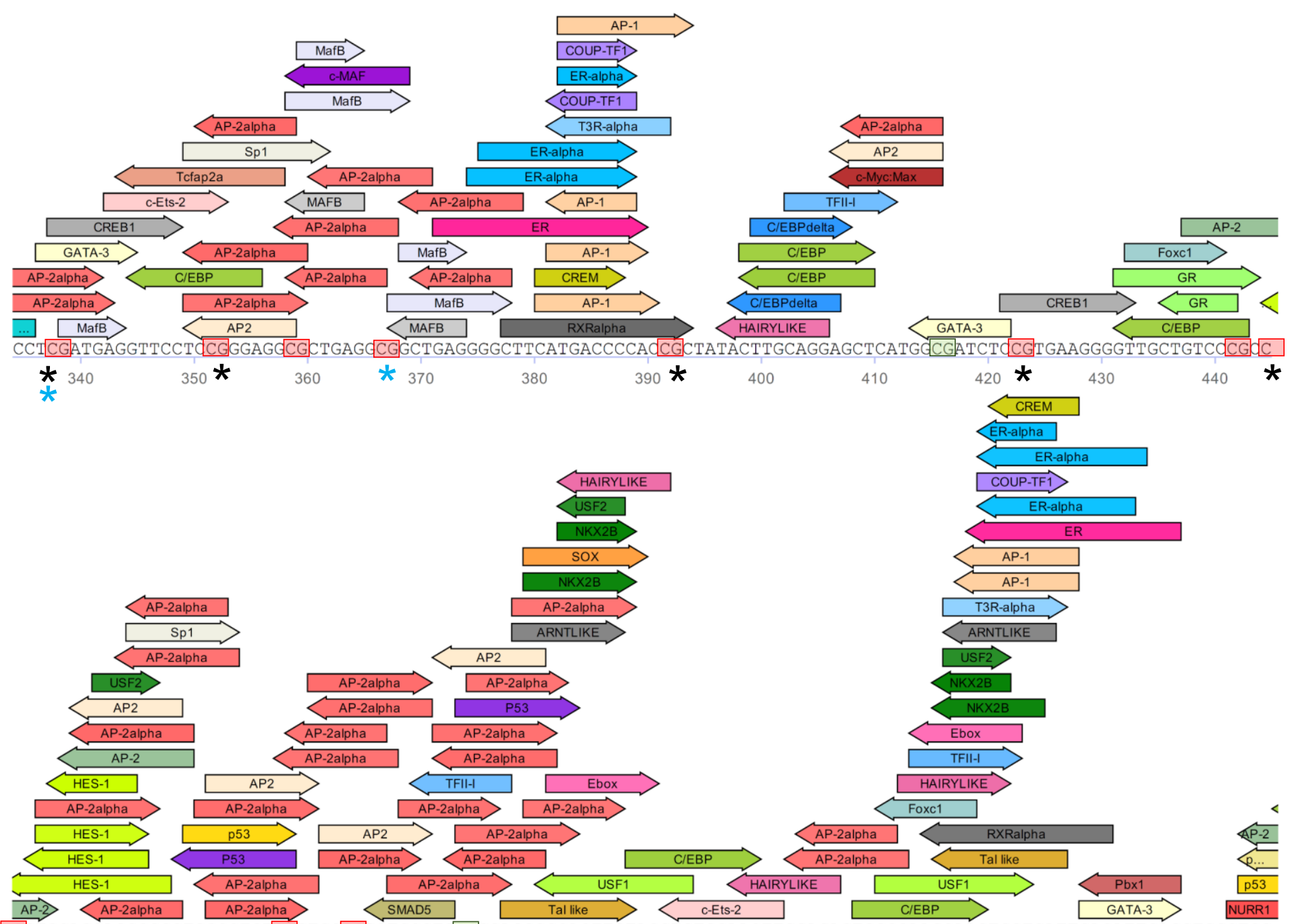

GGTGCACCAGGGGGCTGGCCTGTCGGTGCCGGCTGCCTdCGCCAGGCCCACTTGTAGCTGTGGAACTTGGAGAGTGGCCAAGCAAGTGGTCATTGAGATTGAGCTGGCTGC
* 450
$460 \quad * 470$
480 * 490
500
510
520
530
540
550
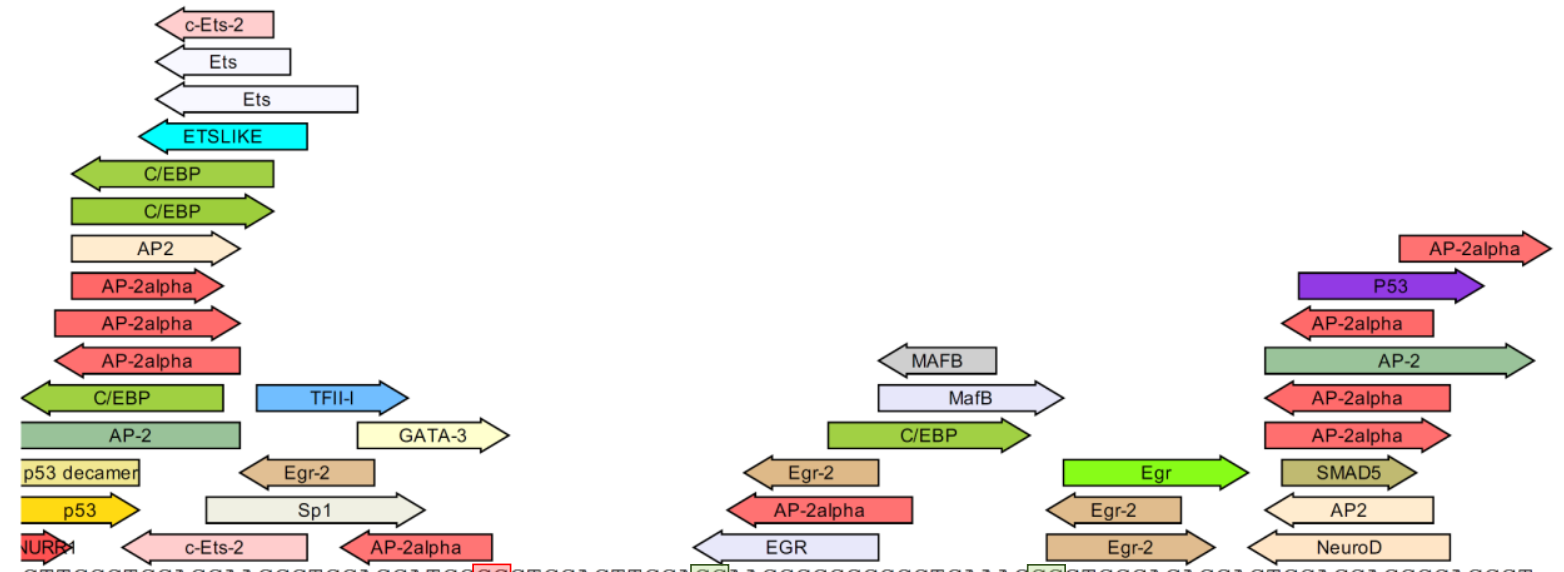

CTTGCCTGGAGGAAGGGTGGAGGATGGCGGTGGAGTTGGACAAAGGGGGGGCCCTGAAAGCGGTGGGAGAGGAGTGCAGCAGGCCAGGGT
560
570
580 * 590
600
610 * 620
630
640
650
660 


\section{Supplemental Figure 5}

$\mathbf{a}$

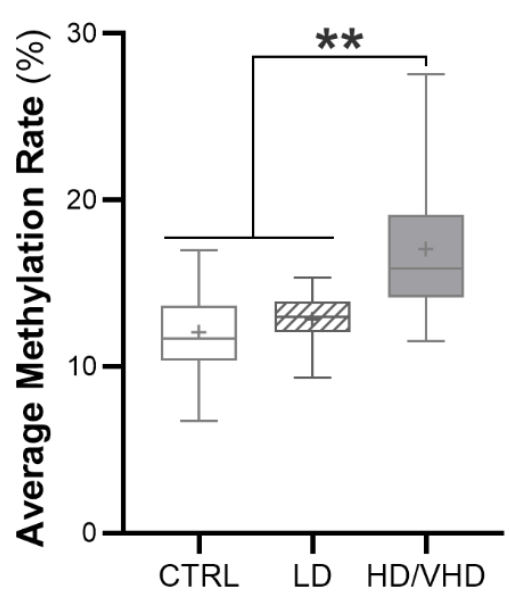

b

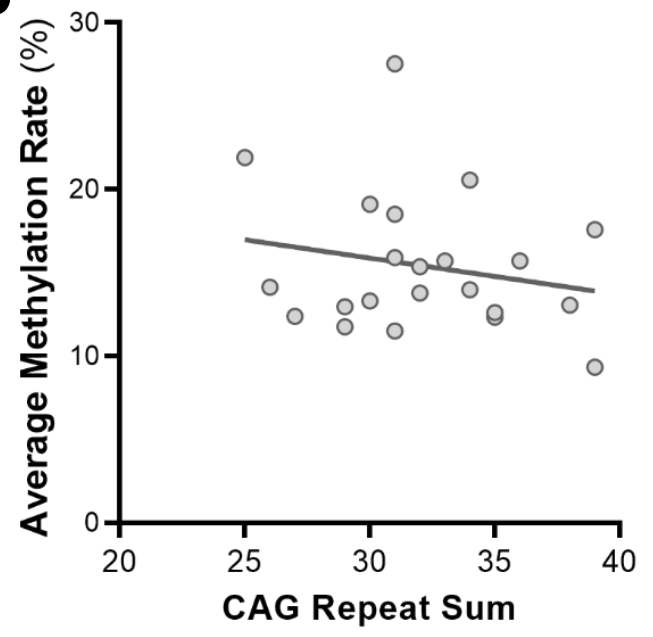

Supplemental Fig. 5. Averaged methylation rate (\%) grouped by drinking class for all $\mathrm{CpGs}$ in male and female rhesus macaques. a The methylation rate was significantly higher in the HD/VHD $(\mathrm{N}=15)$ compared to control $(\mathrm{N}$ $=13)$ and $\mathrm{LD}(\mathrm{N}=9)$ macaques $\left(\mathrm{F}(2,34)=9.860, p=0.0004\right.$, Tukey post-hoc, $\left.{ }^{\star *} p<0.01\right)$. $\mathbf{b}$ Lack of correlation between average methylation rate and CAG repeat sum $(p=0.3563)$ 